\title{
COMPORTAMENTO GEOQUÍMICO DE ETR DURANTE EVOLUÇÃO MAGMÁTICA E ALTERAÇÃO HIDROTERMAL DE GRANITOS: EXEMPLOS DA PROVIINCIA ESTANÍFERA DE GOIÁS
}

\author{
LUCIANA MIYAHARA TEIXEIRA ${ }^{1,2}$ \& NILSON FRANCISQUINI BOTELHO ${ }^{2}$
}

\begin{abstract}
Resumo Os maciços graníticos do tipo A das Subprovíncias Estaníferas Paranã (SPP) e Tocantins (SPT) possuem concentrações anômalas de Elementos Terras Raras (ETR) que, em muitos locais, ultrapassam 1000 vezes o observado em condritos. Os granitos da SPP são individualizados em duas suítes: g1, de tendência alcalina a subalcalina, constituída pelas fácies g1a, g1b e g1c; e g2, de tendência metaluminosa a peraluminosa, constituída pelas fácies g2b, g2c e g2d. O Maciço Serra Dourada (MSD), pertencente à SPT, é constituído pelas fácies de borda, principal e porfirítica. Nos maciços da SPP, foram identificados: apatita, allanita, bastnaesita, oxifluoreto de ETR, fluocerita, zircão, xenotima, torita e monazita como minerais portadores de ETR. Destes, apenas a torita não foi encontrada no MSD (SPT). Os Elementos Terras Raras Leves (ETRL) apresentam comportamento incompatível no início da evolução dos granitos g1, tornando-se compatíveis na fácies g1b. Os Elementos Terras Raras Pesadas (ETRP) apresentam caráter incompatível durante a evolução dos granitos g1, tornando-se compatíveis apenas ao final da mesma. Na suíte g2 os ETRL mostram um caráter compatível desde o início da evolução magmática, enquanto os ETRP praticamente não variam nesse processo. No MSD, não há variação significativa nos ETRL durante a evolução magmática, enquanto os ETRP apresentam caráter compatível. Em todos os casos o comportamento dos ETR está em acordo com uma evolução magmática por cristalização fracionada. Os ETR mostram um comportamento contrastante durante a alteração hidrotermal das SPP e SPT. Nos maciços da SPP, na qual se tem principalmente greisenização, há o empobrecimento nos ETR nesse processo. No MSD, onde predomina a albitização e a biotitização, os ETR se enriquecem em rocha com a alteração hidrotermal. A allanita e a monazita e, quando presentes, a bastnaesita e o oxifluoreto de ETR, são os responsáveis pelos conteúdos de ETRL em rocha, enquanto minerais como zircão, xenotima e torita praticamente não influenciam na quantidade desses elementos. Os minerais portadores de ETRL também alojam uma porção significativa dos ETRP em rocha, acompanhados por xenotima e, quando presente, torita. $\mathrm{O}$ zircão, embora seja o acessório mais comum e, em algumas amostras, extremamente rico em Y e ETRP, praticamente não influencia nos conteúdos dos ETR em rocha.
\end{abstract}

Palavras chave: elementos terras raras, granitos estaníferos, alteração hidrotermal, minerais portadores de ETR.

\begin{abstract}
REE GEOCHEMICAL BEHAVIOUR DURING MAGMATIC EVOLUTION AND HYDROTHERMAL ALTERATION OF GRANITES: EXAMPLES OF THE GOIÁS TIN PROVINCE. The A-type granitic massifs of the Paranã (SPP) and Tocantins (SPT) tin sub-provinces have anomalous rare earth element (REE) contents, sometimes $10^{3}$ greater than the chondrite. Two suites of granitic rocks are present in the SPP, g1 and g2. Rocks of g1 suite (g1a, g1b and g1c facies) display an alkalic affinity whereas g2 granites (g2b, g2c and g2d facies) are metaluminous to peraluminous. Granites of the Serra Dourada Massif, in the SPT, are distributed between Border, Main and Porphiritic facies. REE-bearing minerals described in these rocks are apatite, allanite, monazite, basnäesite, REE-oxyfluorides, fluocerite, zircon and xenotime. Those, only thorite wasn't observed in the Serra Dourada Massif (SPT). The REE are incompatible at the early stages of g1 magma evolution and compatible at the late stages. In all g2 granites, LREE are compatible, whereas HREE concentrations remain unchanged during magma differentiation. In the Serra Dourada granites, the LREE contents are almost constant in all facies while the HREE are incompatible. In all situations, the REE behavior is in agreement with a magma evolution by fractional crystallization. The REE behavior during hydrothermal alteration is contrasting between different granites of both sub-provinces In the SPP massifs, where greisenization dominates, the amount of REE decreases in the altered rocks, whereas in the Serra Dourada Massif, where albitization and biotitization are the main alteration process, the amount of REE increases in the altered rocks. LREE patterns and LREE concentrations of the granites and altered rocks are controlled by allanite, monazite, apatite and the secondary REE minerals. Except for apatite, all these minerals are also important HREE carriers, controlling HREE patterns together with xenotime and thorite. The influence of zircon in these parameters is inexpressive, despite its importance as the main accessory mineral and its enrichment in Y and HREE in some granites.
\end{abstract}

Keywords: rare-earth elements, tin granites, hydrothermal alteration, REE-bearing minerals.

INTRODUÇÃO Os Elementos Terras Raras (ETR) constituem um grupo coerente de elementos, cujos componentes apresentam comportamento químico semelhante (Henderson 1984, 1996). São comumente considerados como elementos pouco móveis, tendendo a permanecer no sistema quando do hidrotermalismo ou metamorfismo (Henderson 1996), sendo importantes indicadores petrogenéticos, já que mudanças nos padrões de ETR de uma suíte de rochas estão diretamente relacionadas com os coeficientes de distribuição mineral/líquido dos elementos envolvidos (Hanson 1989). Entretanto, os ETR podem ser mobilizados durante o metamorfismo/hidrotermalismo na forma de complexos com $\mathrm{F}^{-}, \mathrm{Cl}^{-},\left(\mathrm{SO}_{4}\right)^{2-},\left(\mathrm{CO}_{3}\right)^{2-}$, entre outros (Kosterin 1959, Alderton et al. 1980, Baker 1985, Cathelineau 1987, Charoy \& Pollard 1989, Wood 1990, Bau 1991 entre outros).

Minerais portadores de ETR tais como apatita $\left[\mathrm{Ca}_{5}\left(\mathrm{PO}_{4}\right)_{3}\right.$ $(\mathrm{OH}, \mathrm{F}, \mathrm{Cl})]$, zircão $\left[\mathrm{ZrSiO}_{4}\right]$, allanita $\{(\mathrm{Ca}, \mathrm{Mn}, \mathrm{Ce}, \mathrm{La}, \mathrm{Y}$, $\left.\mathrm{Th})_{2}\left(\mathrm{Fe}^{2+}, \mathrm{Fe}^{3+}, \mathrm{Ti}\right)\left(\mathrm{Al}, \mathrm{Fe}^{3+}\right)_{2} \mathrm{O} . \mathrm{OH}\left[\mathrm{Si}_{2} \mathrm{O}_{7}\right]\left[\mathrm{SiO}_{4}\right]\right\}$ e monazita $\left[(\mathrm{Ce}, \mathrm{La}, \mathrm{Nd}, \mathrm{Th}) \mathrm{PO}_{4}\right]$ são acessórios comuns em rochas de composição granítica a sienítica (Speer 1982a e b, Chang et al. 1996 e Deer et al. 1997). Quando presentes, esses minerais retêm a maior parte dos ETR em rocha, controlando a forma dos padrões de ETR da rocha e o comportamento dos ETR ao longo

\footnotetext{
1 - Instituto Brasileiro do Meio Ambiente e Recursos Naturais Renováveis - IBAMA - - Rua 68, nº 553, apto 303, Centro, Goiânia Goiás - 74055-100. e-mail: lumiyahara@yahoo.com.br
}

2 - Instituto de Geociências - Universidade de Brasília - Instituto de Geociências - Universidade de Brasília - CEP 70910-900, Brasília - DF.e-mail: nilsonfb@unb.br 
de processos como evolução magmática, alteração hidrotermal e metamorfismo (Jefferies 1985, Hanson 1989, Ward et al. 1992, Franz et al. 1996).

GEOLOGIA REGIONAL A Província Estanífera de Goiás é constituída por uma série de depósitos de estanho, hospedados em maciços graníticos de idade paleo a neoproterozóica, individualizados em quatro subprovíncias por Marini \& Botelho (1986), dentre as quais, as subprovíncias Tocantins (SPT) e Paranã (SPP), localizadas ao norte do estado de Goiás (figura 1) e abordadas neste estudo. Essas duas subprovíncias são constituídas por granitos do tipo A intrusivos em paragnaisses e micaxistos da Formação Ticunzal e em milonitos graníticos, granitos e pegmatitos peraluminosos, alguns também estaníferos, da Suíte Aurumina (Botelho et al. 1999, Lacerda Filho et al. 1999) (figura 1). As encaixantes metassedimentares possuem idade mínima paleoproterozóica e os granitos peraluminosos mais recentes têm entre 2,0 e 2,2 Ga (Pereira 2001). Os maciços graníticos e suas encaixantes são recobertos pelos grupos Araí (quartzitos, metassiltitos e filitos com vulcanismo bimodal na sua porção basal) e Serra da Mesa (micaxistos, quartzitos, calcixistos e mármores), que se depositaram em ambiente de rifte continental (Marini et al. 1977, Alvarenga et al. 2000). Pimentel et al. (1991) obtiveram uma idade U-Pb em zircão de $1771 \pm$ 2 Ma para os riolitos da base do Grupo Araí. Todo o conjunto apresenta metamorfismo e deformação. Na SPP, situada mais a leste (figura 1), o metamorfismo é incipiente ou de fácies xisto verde baixo, com preservação de texturas e estruturas primárias nas rochas ígneas e sedimentares do rifte. Na SPT, situada mais a oeste (figura 1), o metamorfismo é de fácies anfibolito médio a alto e as rochas mostram recristalização metamórfica.

Os granitos da SPP foram compartimentados em duas suítes por Botelho (1992): a suíte g1, de tendência alcalina a subalcalina, com elevados conteúdos em $\mathrm{Nb}, \mathrm{Zr}$, Th, Y e ETR, idade de 1,77Ga (Pimentel et al. 1991) e constituída pelas fácies: $g 1 a$ - granodiorito apresentando quartzo, albita, feldspato potássico e biotita como constituintes maiores e ilmenita, apatita, zircão e allanita como acessórios; $g 1 b$ - granito rosa porfirítico constituído por quartzo, microclínio, plagioclásio e biotita, com zircão, allanita e apatita como acessórios; e $g l c$ - granito rosa constituído por quartzo, microclínio, albita e biotita, com ilmenita, monazita e torita $\left(\mathrm{ThSiO}_{4}\right)$ como acessórios. Granitos g1 reequilibrados hidrotermalmente mostram recristalização do quartzo, transformação da biotita (annita) em siderofilita e desestabilização de fases acessórias primárias, como apatita e allanita, em minerais secundários como a britholita $-(\mathrm{Ce}, \mathrm{Y}, \mathrm{Ca})_{5}\left[(\mathrm{P}, \mathrm{Si})_{4}\right]_{3}$ $(\mathrm{OH}, \mathrm{F}, \mathrm{Cl})-\mathrm{e}$ a bastnaesita - $(\mathrm{La}, \mathrm{Ce}, \mathrm{Nd})\left(\mathrm{CO}_{3}\right) \mathrm{F}$. Greisens desenvolvidos sobre granitos g1 caracterizam-se por apresentar uma associação de topázio - siderofilita litinífera ou quartzo - fengita litinífera, com neoformação de minerais como clorita,

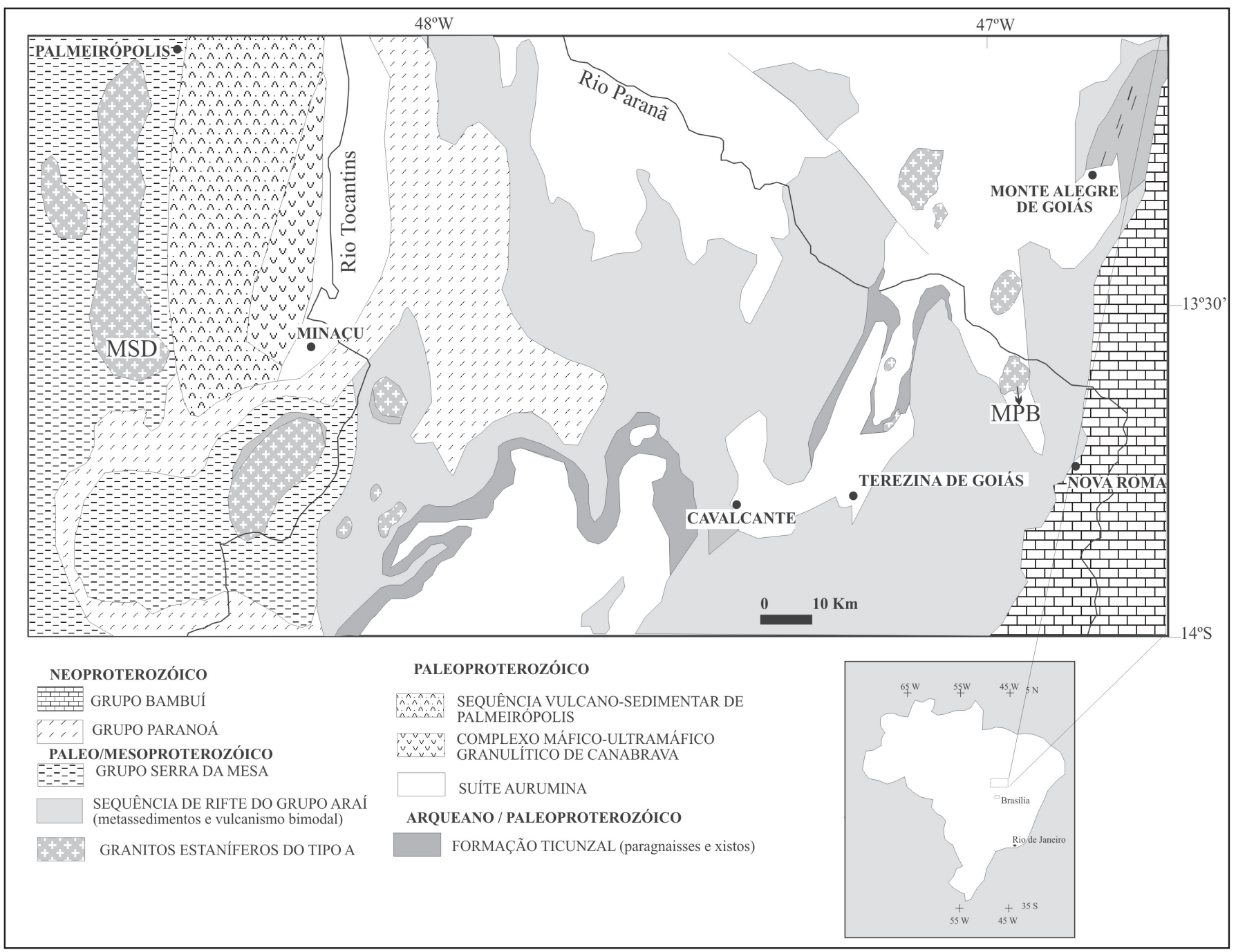

Figura 1 - Mapa geológico simplificado das subprovíncias Tocantins e Paranã (MSD - Maciço Serra Dourada, MPB - Maciço Pedra Branca). 
magnetita e monazita (Botelho 1992).

A suíte $\mathbf{2} 2$ possui caráter metaluminoso a peraluminoso, baixa razão $\mathrm{Na} / \mathrm{K}$ e conteúdos mais elevados em $\mathrm{Li}, \mathrm{Rb}, \mathrm{Sn}$ e Ta quando comparados com a suíte g1. É constituída pelas fácies $g 2 b$ - granito cinza de granulação grossa e textura porfirítica, apresentando microclínio pertítico, plagioclásio, quartzo e biotita como minerais essenciais e zircão, allanita, fluorita, apatita e xenotima $\left(\mathrm{YPO}_{4}\right)$ como acessórios; $g 2 c$ - semelhante ao granito g2b, do qual difere pela granulação mais fina, ausência de apatita e allanita e menor quantidade de zircão; e $g 2 d$ - granito de granulação média a grossa, textura variando de equigranular a porfirítica, muito rico em fluidos que provocaram o seu autometassomatismo e greisenização das encaixantes (Botelho 1992). Granitos g2 alterados hidrotermalmente mostram transformação da biotita primária em biotita secundária \pm fengita \pm clorita, recristalização do quartzo, reequilíbrio do plagioclásio com formação de albita, calcita, fluorita e muscovita finamente cristalizada, destruição de fases acessórias como apatita e allanita e neoformação de minerais como clorita, magnetita, monazita, rutilo e topázio.

No Maciço Serra Dourada (MSD), único corpo granítico da SPT estudado (figura 1), o litotipo predominante, denominado de Fácies Principal, é um biotita granito rosa constituído por quartzo, microclínio pertítico, oligoclásio e biotita com zircão, apatita, monazita, fluorita, ilmenita, pirita e calcopirita como acessórios (Macambira 1983, Bilal 1991 e Bilal et al. 1997). A Fácies Principal é localmente cortada por veios e filões de granito porfirítico, denominado Fácies Porfirítica e constituído por plagioclásio, quartzo, biotita, allanita e fenocristais tardios de microclínio. Nas bordas do maciço, predomina um ortognaisse milonitizado, denominado de Fácies de Borda e constituído por quartzo, microclínio pertítico, oligoclásio, ferropargasita e biotita, com zircão, apatita, monazita, fluorita e ilmenita como acessórios. As fácies de borda, principal e porfirítica representam uma evolução magmática, com a fácies de borda sendo a menos evoluída e a porfirítica a mais evoluída (Bilal 1991). Embora apresente quartzo - muscovita greisens, a alteração hidrotermal no MSD caracteriza-se pela geração de albititos, constituídos de albita, quartzo, biotita, anfibólio, microclínio e muscovita, com apatita, fluorita, opacos, zircão, granada e titanita como acessórios, e biotititos, com até $98 \%$ de biotita, mais plagioclásio, quartzo, microclínio, muscovita e allanita (Macambira 1983 e Bilal 1991).

MÉTODOS ANALÍTICOS Onze amostras de granito inalterado da SPP foram selecionadas para determinar o comportamento dos ETR ao longo da evolução magmática. Nestas, $\mathrm{SiO}_{2}$, $\mathrm{Al}_{2} \mathrm{O}_{3}, \mathrm{Fe}_{2} \mathrm{O}_{3}, \mathrm{CaO}, \mathrm{K}_{2} \mathrm{O}, \mathrm{P}_{2} \mathrm{O}_{5}, \mathrm{Ga}, \mathrm{Rb}, \mathrm{Y}, \mathrm{Zr}, \mathrm{W}, \mathrm{Sn}, \mathrm{Cs}, \mathrm{Ba}, \mathrm{La}$, $\mathrm{Ce}, \mathrm{Pb}$, Th e $\mathrm{U}$ foram determinados por fluorescência de raios $\mathrm{X}, \mathrm{MnO}, \mathrm{MgO}, \mathrm{Na}_{2} \mathrm{O}, \mathrm{TiO}_{2}, \mathrm{Sc}, \mathrm{Ni}, \mathrm{Cu}, \mathrm{Zn}, \mathrm{Sr}, \mathrm{Nb}, \mathrm{Nd}, \mathrm{Sm}, \mathrm{Eu}$, Dy, Yb, Th, Be e Li por IČP-AES e Ta e Hf por ativação neutrônica (Laboratório de Geologia da École des Mines de Saint Étienne, França). Outras onze amostras foram selecionadas para se determinar o comportamento dos ETR ao longo da alteração hidrotermal de granitos da SPP. Nestas, Th, Ba, Ta, Nb, Cs, U, $\mathrm{Rb}, \mathrm{Sr}, \mathrm{Y}, \mathrm{Zr}$ e S foram determinados por fluorescência de raios $\mathrm{X}$ enquanto os ETR foram analisados por ICP-AES (GEOSOL). Para a caracterização do comportamento dos ETR durante a alteração hidrotermal do granito Serra Dourada, foram selecionadas sete amostras, onde todos os elementos foram determinados por ativação neutrônica (Laboratório Bondar Clegg - Canadá).

A quantidade de cada mineral acessório identificado em lâmina delgada foi estimada a partir da composição química da amostra (tabela 1) e da composição média do mineral em cada amostra estudada (tabela 2). Deste modo, utilizou-se o conteúdo de Zr para calcular o conteúdo de zircão; os teores em ETRL, subtraindo-se os ETRL devidos ao zircão, para estimar o conteúdo de allanita, monazita, bastnaesita e/ou oxifluoreto de ETR; e assim sucessivamente para todos os minerais portadores de ETR. Entretanto, não foram utilizados teores de Y para calcular o conteúdo de xenotima, pois constatou-se que haveria uma superavaliação da quantidade deste mineral e, conseqüentemente, dos ETRP. Isto se deve à presença de $\mathrm{Y}$ em minerais não utilizados nesse cálculo, como a apatita, ou à presença de outras fases portadoras de $\mathrm{Y}$ ainda não identificadas.

A composição química dos minerais foi obtida em Microssonda Eletrônica SX50 dos laboratórios do Instituto de Geociências da Universidade de Brasília e do Bureau des Recherches Géologiques et Minières - BRGM - França. Ambas estão equipadas com sistema de dispersão de wave lenght, ângulo de take off de $40^{\circ}$, tendo sido aplicando o procedimento de correção PAP.

Para zircão e xenotima foi utilizada voltagem de aceleração de $20 \mathrm{kV}$, corrente de $40 \mathrm{nA}$ e tempo de contagem de $10 \mathrm{~s}$ para $\mathrm{Si}, \mathrm{Zr}, \mathrm{P}, \mathrm{U}, \mathrm{Hf}$ e Th e voltagem de aceleração de $25 \mathrm{kV}$, corrente de 200 nA e tempo de contagem de 20 s para $\mathrm{Nb}$, Y e ETR. Nos demais minerais analisados, utilizou-se uma voltagem de aceleração de $15 \mathrm{kV}$, corrente de $25 \mathrm{nA}$ e tempo de contagem de 10s para $\mathrm{P}, \mathrm{Ca}, \mathrm{F}, \mathrm{Si}, \mathrm{Zr}, \mathrm{U}, \mathrm{Th}, \mathrm{Fe}, \mathrm{Al}$, Ti e Mn e voltagem de aceleração de $20 \mathrm{kV}$, corrente de $40 \mathrm{nA}$ e tempo de contagem de 20s para Y e os ETR.

Foram usadas as linhas $\mathrm{K} \alpha$ para $\mathrm{Si}, \mathrm{P}, \mathrm{Ca}, \mathrm{F}, \mathrm{Fe}, \mathrm{Al}$, Ti e Mn; $\mathrm{L} \alpha$ para $\mathrm{Y}, \mathrm{Hf}, \mathrm{Nb}, \mathrm{La}, \mathrm{Ce}, \mathrm{Eu}, \mathrm{Er}, \mathrm{Yb}$; L $\beta$ para Pr, Nd, Sm, Gd e Dy e M $\alpha$ para U e Th. Fez-se a correção do LaL $\alpha$ no Pr, CeL $\beta$ no Nd, Pr L $\beta$ no Eu e CeL $\gamma$ no Gd utilizando-se os parâmetros de Åmli \& Griffin (1975). Os cristais analíticos foram LiF para os ETR, TAP para Si, Y, Zr, F e Al e PET para P, U, Th, Nb, Ca e Ti. Como padrões foram usados óxidos sintéticos de ETR, metais puros para $\mathrm{U}$, Ti e $\mathrm{Nb}$ e minerais naturais para os demais elementos.

\section{RESULTADOS E DISCUSSÕES}

Mudanças nos padrões de ETR normalizados a condrito durante a evolução magmática A comparação entre os padrões de ETR normalizados a condrito das fácies que constituem os granitos g1 evidencia aumento significativo nos Elementos Terras Raras Leves (ETRL - do La ao Eu) entre gla e glb, enquanto o Eu permanece aproximadamente constante (figura 2). Algumas amostras de granito glb mostram enriquecimento em Eu, o que foi atribuído a uma acumulação de plagioclásio na rocha ou à formação de fluorita em rochas alteradas hidrotermalmente, enquanto a diminuição nos conteúdos de La e Ce entre granitos g1b menos e mais evoluídos foi atribuída à precipitação de allanita. Ítrio e os Elementos Terras Raras Pesadas (ETRP - do Eu ao Lu) apresentam um caráter incompatível, tornandose compatíveis apenas ao final da evolução magmática (figura 2), de modo que a razão $(\mathrm{La} / \mathrm{Yb})_{\mathrm{N}}$, que varia entre 7 e 9 entre g1a e g1b, diminui para $4 \mathrm{em}$ g1c. Esse comportamento dos ETRP se reflete na química do zircão, que é empobrecido nos mesmos nas fácies gla e g1b e enriquecido na fácies g1c (Teixeira \& Botelho 1999).

Na suíte g2 os padrões de ETR normalizados a condrito (figura 3) mostram que os ETRL apresentam um caráter compatível, com diminuição na sua quantidade entre g2b e g2d. Os ETRP apresentam pouca ou nenhuma variação com a evolução magmática, com enriquecimento de aproximadamente 100 vezes o observado em condritos. Este comportamento se reflete na razão $(\mathrm{La} / \mathrm{Yb})_{\mathrm{N}}$, que varia entre 4 e 5 em g2b e diminui para aproximadamente $1 \mathrm{em}$ g2d.

No Maciço Serra Dourada, os padrões de ETR normalizados a condrito (figura 4) não mostram variação significativa de La, Ce e Y com a evolução magmática enquanto os ETRP 


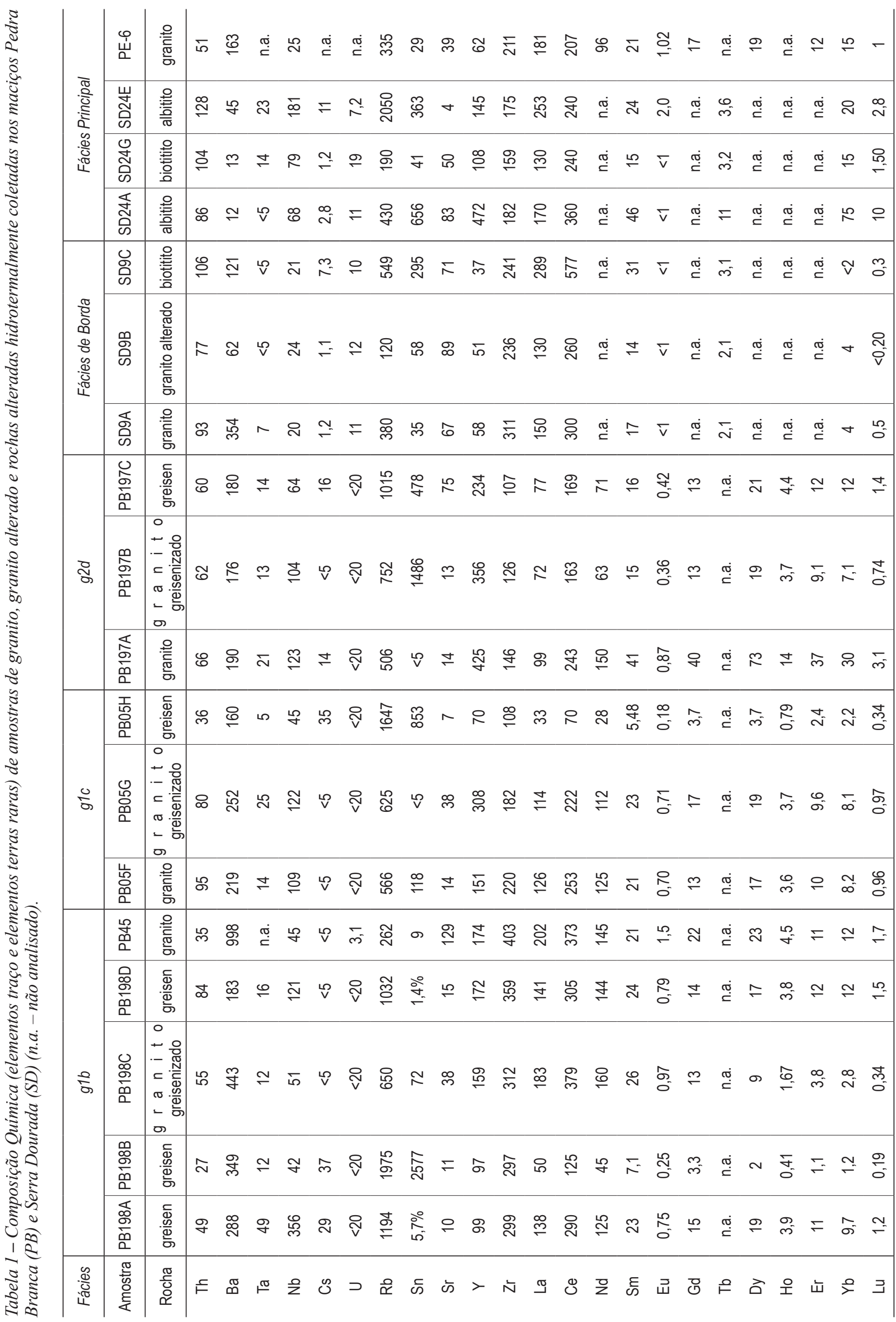




\begin{tabular}{|c|c|c|c|c|c|c|c|c|c|c|c|c|c|c|c|c|c|c|c|c|c|}
\hline \multirow{6}{*}{ \& } & 華 & స్సి & $\frac{\infty}{\dot{0}}$ & $\stackrel{8}{\circ}$ & $\hat{\widehat{o}}$ & $\stackrel{8}{0}$ & $\stackrel{\infty}{\stackrel{\leftrightarrow}{-}}$ & กุ & $\stackrel{8}{0}$ & : & $\stackrel{8}{\circ}$ & $\stackrel{8}{0}$ & $\stackrel{\Xi}{0}$ & $\stackrel{8}{\circ}$ & $\stackrel{8}{0}$ & $\stackrel{8}{\circ}$ & $\stackrel{0}{\circ}$ & $\stackrel{\circ}{\circ}$ & : & $\stackrel{1}{0}$ & \begin{tabular}{l}
7 \\
\hdashline \\
0
\end{tabular} \\
\hline & के & 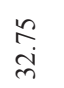 & 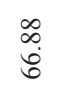 & $\stackrel{8}{\circ}$ & $\stackrel{n}{\circ}$ & $\stackrel{8}{0}$ & io & $\stackrel{d}{0}$ & $\stackrel{8}{\circ}$ & $\stackrel{8}{\circ}$ & $\stackrel{8}{8}$ & $\stackrel{\text { og }}{\circ}$ & $\overline{\overline{0}}$ & $\stackrel{8}{8}$ & $\stackrel{0}{0}$ & $\stackrel{8}{\circ}$ & Бे. & $\overline{0}$ & $\stackrel{8}{8}$ & 营 & $\stackrel{0}{0} \stackrel{0}{0}$ \\
\hline & 商 & 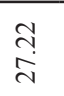 & 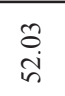 & $\stackrel{8}{\circ}$ & $\stackrel{m}{\dddot{m}}$ & gे. & $\bar{\Phi}$ & $\stackrel{\infty}{=}$ & $\stackrel{8}{0}$ & $\stackrel{0}{\circ}$ & $\stackrel{8}{0}$ & o. & 范 & $\stackrel{\overline{0}}{\circ}$ & ठ̊. & $\overline{0}$ & $\stackrel{8}{8}$ & $\stackrel{\infty}{\circ}$ & $\stackrel{n}{0}$ & : & 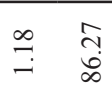 \\
\hline & $\begin{array}{l}n \\
\stackrel{m}{\alpha} \\
2\end{array}$ & $\begin{array}{l}\text { ñ } \\
\text { on } \\
\end{array}$ & $\begin{array}{l}m \\
8 \\
\end{array}$ & $\stackrel{8}{\circ}$ & $\hat{3}$ & $\hat{\widehat{c}}$ & $\stackrel{\circ}{-}$ & $\hat{\widehat{O}}$ & $\stackrel{8}{0}$ & 8 & $\stackrel{8}{0}$ & $\stackrel{0}{0}$ & $\stackrel{8}{0}$ & $\stackrel{8}{0}$ & $\stackrel{0}{0}$ & $\stackrel{8}{\circ}$ & $\stackrel{8}{0}$ & 8 & $\stackrel{8}{8}$ & fo & $n$ \\
\hline & 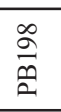 & 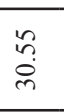 & $\begin{array}{l}\text {. } \\
\text { ñ }\end{array}$ & $\stackrel{8}{0}$ & त̂̀ & $\stackrel{ \pm}{0}$ & $\stackrel{R}{i}$ & $\stackrel{0}{0}$ & 8 & $\stackrel{8}{0}$ & $\stackrel{8}{\circ}$ & $\stackrel{8}{0}$ & $\stackrel{8}{0}$ & $\stackrel{8}{0}$ & $\stackrel{8}{\circ}$ & $\stackrel{8}{\circ}$ & $\stackrel{8}{\circ}$ & $\stackrel{8}{0}$ & 8 & $\overline{0}$ & 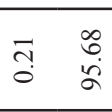 \\
\hline & 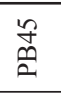 & $\underset{\text { i }}{\bar{m}}$ & $\begin{array}{l}n \\
\hat{3} \\
0\end{array}$ & $\stackrel{8}{\circ}$ & $\stackrel{\infty}{0}$ & $\overrightarrow{0}$ & $\stackrel{\infty}{\underset{\Im}{-}}$ & $\stackrel{0}{\circ}$ & $\stackrel{8}{0}$ & $\stackrel{0}{\circ}$ & $\stackrel{8}{0}$ & $\stackrel{8}{\circ}$ & $\stackrel{8}{0}$ & $\stackrel{\overrightarrow{0}}{0}$ & $\stackrel{8}{\circ}$ & $\overline{0}$ & $\stackrel{8}{0}$ & $\stackrel{0}{\circ}$ & $\stackrel{8}{\circ}$ & $\stackrel{0}{\circ}$ & $\stackrel{\text { no }}{0}$ \\
\hline \multirow{2}{*}{ 营 } & की & $\stackrel{7}{0}$ & $\stackrel{8}{0}$ & $\begin{array}{l}\text { Iy } \\
\text { fid }\end{array}$ & 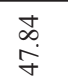 & n̊ & $\stackrel{8}{\circ}$ & $\hat{3}$ & $\stackrel{8}{0}$ & $\stackrel{8}{\circ}$ & $\stackrel{0}{\circ}$ & $\stackrel{8}{0}$ & $\stackrel{8}{0}$ & $\stackrel{8}{\circ}$ & $\overline{0}$ & $\stackrel{8}{\circ}$ & $\stackrel{\circ}{\circ}$ & $\stackrel{m}{m}$ & $\begin{array}{l}n \\
\stackrel{r}{+} \\
\dot{q}\end{array}$ & ले & iे \\
\hline & 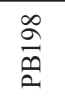 & $\tilde{n}$ & $\stackrel{8}{\circ}$ & $\underset{j}{\stackrel{f}{f}}$ & $\stackrel{\infty}{\stackrel{\infty}{\sigma}}$ & $\stackrel{t}{0}$ & $\stackrel{8}{\circ}$ & ^ึ & 苚 & $\overline{0}$ & o. & $\stackrel{8}{\circ}$ & : & 7 & $\stackrel{\infty}{0}$ & $\overline{\text { वे }}$ & $\stackrel{\text { o. }}{0}$ & $\underset{+}{\stackrel{\leftrightarrow}{+}}$ & 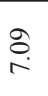 & 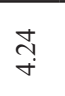 & $\begin{array}{c}\hat{n} \\
\dot{q} \\
\dot{\alpha} \\
\alpha\end{array}$ \\
\hline \multirow{3}{*}{ 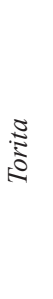 } & $\overline{b D}$ & $\stackrel{\hat{m}}{\stackrel{\tilde{m}}{ \pm}}$ & $\stackrel{ \pm}{\circ}$ & तે & $\ddot{m}$ & $\vec{r}$ & 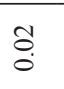 & $\begin{array}{l}\infty \\
\infty \\
\tilde{\gamma}\end{array}$ & $\stackrel{0}{0}$ & $\stackrel{0}{\circ}$ & $\stackrel{8}{0}$ & $\overline{0}$ & 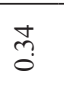 & $\stackrel{\infty}{\circ}$ & กิ & $\stackrel{9}{\circ}$ & 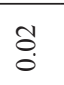 & î. & $\stackrel{n}{:}$ & : & $\stackrel{\substack{f \\
\delta}}{0}$ \\
\hline & $\stackrel{\hat{a}}{\stackrel{0}{\approx}}$ & $\begin{array}{l}0 \\
\stackrel{0}{2} \\
\end{array}$ & $\stackrel{t}{0}$ & $\stackrel{\infty}{\stackrel{-}{-}}$ & $\vec{b}$ & $\stackrel{\overbrace{}}{i}$ & 苛 & $\underset{m}{\stackrel{\infty}{n}}$ & $\stackrel{8}{0}$ & $\stackrel{8}{\circ}$ & $\stackrel{8}{\circ}$ & $\tilde{O}$ & $\stackrel{\circ}{\circ}$ & $\stackrel{8}{\circ}$ & $\stackrel{\infty}{\circ}$ & $\stackrel{0}{\circ}$ & $\stackrel{\square}{0}$ & $\tilde{0}$ & $\stackrel{9}{\rightrightarrows}$ & 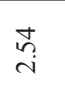 & 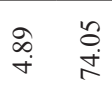 \\
\hline & 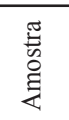 & $O_{i n}^{N}$ & 泉 & $0^{n}$ & $\stackrel{\overbrace{}^{\prime}}{\gamma^{\prime}}$ & $\rho^{\prime}$ & $\stackrel{Q}{ \pm}^{\sim}$ & $\mathscr{\bigodot}^{N}$ & $\stackrel{8}{~}$ & $\frac{0^{n}}{\mathbb{Z}^{-1}}$ & $\begin{array}{l}0^{n} \\
z^{n}\end{array}$ & $\begin{array}{l}0 \\
\tilde{J}^{\prime \prime}\end{array}$ & $\begin{array}{l}0 \\
\delta^{\circ}\end{array}$ & 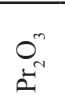 & $\begin{array}{l}0^{\prime \prime} \\
\vec{z}\end{array}$ & $\begin{array}{l}\text { On } \\
\tilde{E}^{n}\end{array}$ & $\begin{array}{l}0^{m} \\
\vec{y}^{-1}\end{array}$ & $\begin{array}{l}0^{\prime \prime} \\
\mathbb{E}^{\prime \prime}\end{array}$ & م. & $\begin{array}{ll}0 \\
\text { int }\end{array}$ & $\begin{array}{l}0^{-\infty} \\
\sum^{-1}\end{array}$ \\
\hline \multirow{4}{*}{ 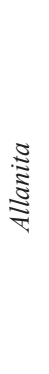 } & कิ & $\begin{array}{l}\infty \\
\stackrel{\infty}{\circ} \\
\text { ji }\end{array}$ & in & î & $\stackrel{0}{0}$ & $\begin{array}{l}\stackrel{b}{0} \\
\end{array}$ & $\begin{array}{l}0 \\
\infty \\
\infty \\
\infty\end{array}$ & $\stackrel{\infty}{\circ}$ & $\stackrel{8}{0}$ & $\stackrel{\Xi}{ت}$ & $\overline{5}$ & $\underset{\infty}{\infty}$ & $\stackrel{\infty}{\infty} \underset{0}{\infty}$ & $\stackrel{\infty}{\infty}$ & 号 & $\hat{a}$ & กี่ & ț & $\begin{array}{c}\infty \\
\stackrel{\infty}{0} \\
o\end{array}$ & $\stackrel{8}{\circ}$ & \\
\hline & कू & 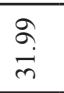 & तิ & 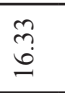 & $\stackrel{8}{0}$ & $\begin{array}{l}\stackrel{f}{+} \\
\dot{I}\end{array}$ & $\stackrel{\infty}{\circ}$ & $\tilde{3}$ & $\stackrel{8}{0}$ & $\stackrel{\infty}{0}$ & 每 & $\stackrel{5}{=}$ & $\exists$ & $\underset{\substack{n \\
\dot{r}}}{ }$ & : & $\stackrel{m}{o}$ & $\frac{n}{0}$ & $\stackrel{\tilde{\sigma}}{\circ}$ & $\stackrel{\infty}{0}$ & $\begin{array}{l}3 \\
\stackrel{3}{a}\end{array}$ & \\
\hline & कD & के & in & $\begin{array}{l}\dot{\infty} \\
\stackrel{\infty}{=}\end{array}$ & $\underset{m}{=}$ & $\stackrel{\infty}{\stackrel{\infty}{n}}$ & $\bar{a}$ & $\stackrel{\infty}{0}$ & $\stackrel{8}{\circ}$ & $\stackrel{\vec{\sigma}}{\dot{\sigma}}$ & $\stackrel{\vec{\sigma}}{i}$ & $\stackrel{\Xi}{\Xi}$ & Iิ & $\underset{\substack{\infty \\
\dot{\gamma}}}{2}$ & 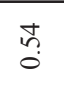 & రై & $\stackrel{n}{0}$ & $\stackrel{0}{\circ}$ & @ె & बे & \\
\hline & $\begin{array}{l}\text { 妥 } \\
\text { 是 }\end{array}$ & $\stackrel{O}{ }^{N}$ & $\wp_{\exists}^{\sigma}$ & $\stackrel{O^{n}}{\vec{\varangle}^{n}}$ & ○ & $\begin{array}{l}0^{n} \\
\omega^{\infty}\end{array}$ & O & $\stackrel{\circ}{\Xi}$ & $\rho^{\sim}$ & $\stackrel{ᄋ}{F}^{\sim}$ & $\begin{array}{l}O^{n} \\
\tilde{J}^{\prime \prime}\end{array}$ & $\begin{array}{l}0 \\
0^{\prime \prime}\end{array}$ & On & $\begin{array}{l}O^{n} \\
\vec{n}^{n}\end{array}$ & $\begin{array}{l}0^{\infty} \\
\tilde{E}^{n}\end{array}$ & $\begin{array}{l}0^{n} \\
\tilde{J}^{\prime \prime}\end{array}$ & $0^{n}$ & $\begin{array}{l}0^{\infty} \\
e^{-1}\end{array}$ & $\overbrace{>}^{\infty}$ & 急 & \\
\hline \multirow{5}{*}{ 莺 } & 苑 & $\begin{array}{c}n \\
a \\
a j \\
d\end{array}$ & \% & 常 & $\underset{i}{\Delta}$ & tr & $\stackrel{8}{0}$ & $\stackrel{\bar{\omega}}{\circ}$ & $\begin{array}{l}\text { ô. } \\
\stackrel{0}{0}\end{array}$ & in & ب̣ & $\stackrel{0}{0}$ & สู่ & $\tilde{m}$ & $\stackrel{\infty}{0}$ & $\stackrel{\circ}{0}$ & $\begin{array}{l}n \\
\vdots \\
0 \\
0\end{array}$ & & & & \\
\hline & ב్ & $\stackrel{\bar{i}}{a}$ & $\stackrel{7}{0}$ & $\stackrel{n}{n}$ & के & : & 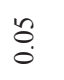 & $\begin{array}{l}\stackrel{\rho}{+} \\
\stackrel{+}{+}\end{array}$ & 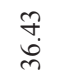 & fु & $\stackrel{\infty}{\stackrel{\infty}{0}}$ & $\stackrel{?}{\stackrel{f}{-}}$ & กิ & के & $\stackrel{0}{\circ}$ & $\stackrel{8}{0}$ & $\stackrel{\infty}{\infty}$ & & & & \\
\hline & 簽 & 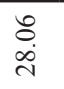 & $\frac{9}{0}$ & $\stackrel{\infty}{\stackrel{n}{?}}$ & $\stackrel{\infty}{\infty}$ & $=$ & $\stackrel{8}{\circ}$ & 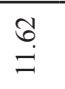 & 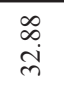 & ले & $\begin{array}{l}\stackrel{8}{6} \\
\stackrel{7}{7}\end{array}$ & 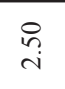 & $\vec{n}$ & $\stackrel{\infty}{\infty}$ & $\stackrel{0}{0}$ & $\vec{\circ}$ & 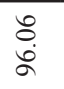 & & & & \\
\hline & $\stackrel{\infty}{\stackrel{\infty}{\cong}}$ & $\begin{array}{l}\infty \\
\substack{\infty \\
\infty \\
\sim}\end{array}$ & $\stackrel{m}{0}$ & $\stackrel{\tilde{m}}{-}$ & Iั. & $\stackrel{?}{f}$ & $\stackrel{7}{0}$ & $\begin{array}{l}\bar{m} \\
\underline{n}\end{array}$ & 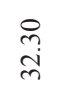 & 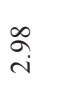 & ֻٕ: & $\stackrel{+}{\infty}$ & : & $\stackrel{\infty}{\stackrel{\infty}{-}}$ & $\begin{array}{l}\infty \\
\stackrel{0}{o}\end{array}$ & $\overrightarrow{0}$ & $\begin{array}{l}\overline{0} \\
\text { o }\end{array}$ & & & & \\
\hline & $\begin{array}{l}\text { 㸓 } \\
\text { 是 }\end{array}$ & $\stackrel{0}{n}_{0^{n}}^{n}$ & ల్ల & 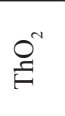 & $\mathscr{0}^{\sim}$ & $\stackrel{\overbrace{}^{\prime}}{n}$ & $\rho^{\alpha}$ & $\begin{array}{l}0^{m} \\
\tilde{J}^{\prime \prime}\end{array}$ & $\begin{array}{l}0^{\prime \prime} \\
0^{\circ}\end{array}$ & 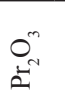 & $\begin{array}{l}0^{m} \\
\vec{z}^{n}\end{array}$ & $\begin{array}{l}0^{n} \\
E^{n}\end{array}$ & $\begin{array}{l}0 \\
0^{n} \\
\underbrace{n}\end{array}$ & $\begin{array}{l}0^{\prime \prime} \\
\mathbb{E}^{\prime \prime}\end{array}$ & $0^{\prime \prime}$ & $\begin{array}{l}\text { On}^{\prime \prime} \\
\dot{\phi}^{n}\end{array}$ & 喼 & & & & \\
\hline \multirow{2}{*}{$\begin{array}{l}\frac{0}{5} \\
\frac{5}{5} \\
5 \\
5\end{array}$} & $\stackrel{\infty}{\stackrel{\infty}{\cong}}$ & 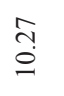 & $\stackrel{\overbrace{}}{0}$ & E. & $\stackrel{\infty}{\stackrel{0}{0}}$ & $\stackrel{\tilde{o}}{\circ}$ & $\bar{n}$ & \begin{tabular}{l}
\multirow{2}{*}{} \\
di
\end{tabular} & $\begin{array}{l}\bar{\infty} \\
\infty \\
\infty \\
\infty\end{array}$ & $\underset{\infty}{\infty}$ & $\begin{array}{c}\hat{0} \\
\infty\end{array}$ & $\begin{array}{l}\stackrel{2}{0} \\
0\end{array}$ & $\vec{n}$ & fै. & $\stackrel{t}{0}$ & $\stackrel{\delta}{0}$ & $\stackrel{8}{0}$ & ָุ & 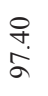 & $\underset{\widetilde{F}}{\stackrel{y}{f}}$ & $\stackrel{\infty}{\infty}$ \\
\hline & की & $\underset{\alpha}{\alpha}$ & $\ddot{\circ}$ & $\stackrel{\infty}{\stackrel{\infty}{\circ}}$ & $\stackrel{0}{\circ}$ & $\stackrel{\leftrightarrow}{\circ}$ & $\stackrel{\text { I }}{\text {. }}$ & $\begin{array}{l}\dot{y} \\
\dot{d} \\
\dot{d}\end{array}$ & $\begin{array}{l}\tilde{N} \\
\infty \\
\infty\end{array}$ & $\underset{ָ}{\stackrel{m}{i}}$ & : & fof & 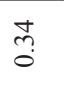 & $\overline{\text { ปุ }}$ & $\stackrel{8}{0}$ & $\stackrel{\check{O}}{\circ}$ & ă. & त̦ & $\begin{array}{l}\widehat{\infty} \\
\dot{\infty} \\
\infty\end{array}$ & 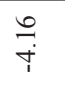 & $\underset{\infty}{\stackrel{R}{\infty}}$ \\
\hline \multirow{3}{*}{ 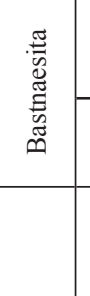 } & $\stackrel{\infty}{\stackrel{\infty}{\dddot{m}}}$ & $\stackrel{\text { }}{\stackrel{\varrho}{\circ}}$ & $\stackrel{\overbrace{}}{0}$ & తి & $\overline{0}$ & $\overline{0}$ & $\stackrel{n}{0}$ & $\begin{array}{l}\stackrel{+}{\infty} \\
\stackrel{D}{\varrho}\end{array}$ & $\begin{array}{l}\stackrel{0}{2} \\
\stackrel{్}{0}\end{array}$ & $\stackrel{\vartheta}{r}$ & $\begin{array}{l}\stackrel{0}{+} \\
\stackrel{0}{\subseteq}\end{array}$ & $\stackrel{\infty}{\stackrel{i}{i}}$ & ñ & $\stackrel{8}{-}$ & 孛 & $\overline{0}$ & $\stackrel{0}{\circ}$ & $\ddot{0}$ & $\underset{\substack{\infty \\
\infty \\
\infty}}{\stackrel{0}{2}}$ & 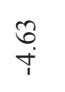 & $\underset{\infty}{f}$ \\
\hline & के & t. & $\stackrel{n}{0}$ & $\bar{\sigma}$ & 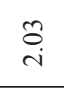 & $\stackrel{\infty}{0}$ & in & $\begin{array}{l}\text { â } \\
\text { bे }\end{array}$ & $\begin{array}{l}\stackrel{\circ}{\circ} \\
\stackrel{2}{2}\end{array}$ & $\underset{i}{i}$ & $\stackrel{\infty}{\stackrel{\infty}{=}}$ & 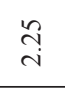 & 京 & $\stackrel{ }{I}$ & $\stackrel{m}{\rightarrow}$ & $\stackrel{\infty}{0}$ & $\stackrel{?}{\leftrightarrows}$ & $\stackrel{m}{m}$ & 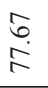 & $\stackrel{\infty}{\vec{f}}$ & 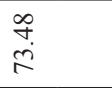 \\
\hline & $\begin{array}{l}\text { 㸓 } \\
\text { 兵 }\end{array}$ & w & $0^{n}$ & ̊ & $0^{N}$ & $\rho^{\sim}$ & 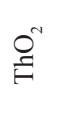 & $\begin{array}{l}0^{m} \\
\tilde{J}^{\prime \prime}\end{array}$ & $\begin{array}{l}0 \\
0^{\infty}\end{array}$ & 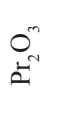 & $\begin{array}{l}\hat{O}^{n} \\
\vec{z}^{n}\end{array}$ & $\begin{array}{l}0 \\
\Xi^{m} \\
n^{n}\end{array}$ & $\begin{array}{l}0 \\
3^{\prime \prime} \\
\exists^{n}\end{array}$ & $\begin{array}{l}O^{m} \\
\mathbb{S}^{n}\end{array}$ & $\stackrel{0}{\widehat{n}}$ & $\begin{array}{l}0^{n} \\
\hat{D}^{n}\end{array}$ & $\begin{array}{l}0^{m} \\
\omega^{-1}\end{array}$ & $\stackrel{0}{\lambda^{\infty}}$ & 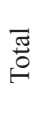 & 乔 & 急 \\
\hline
\end{tabular}




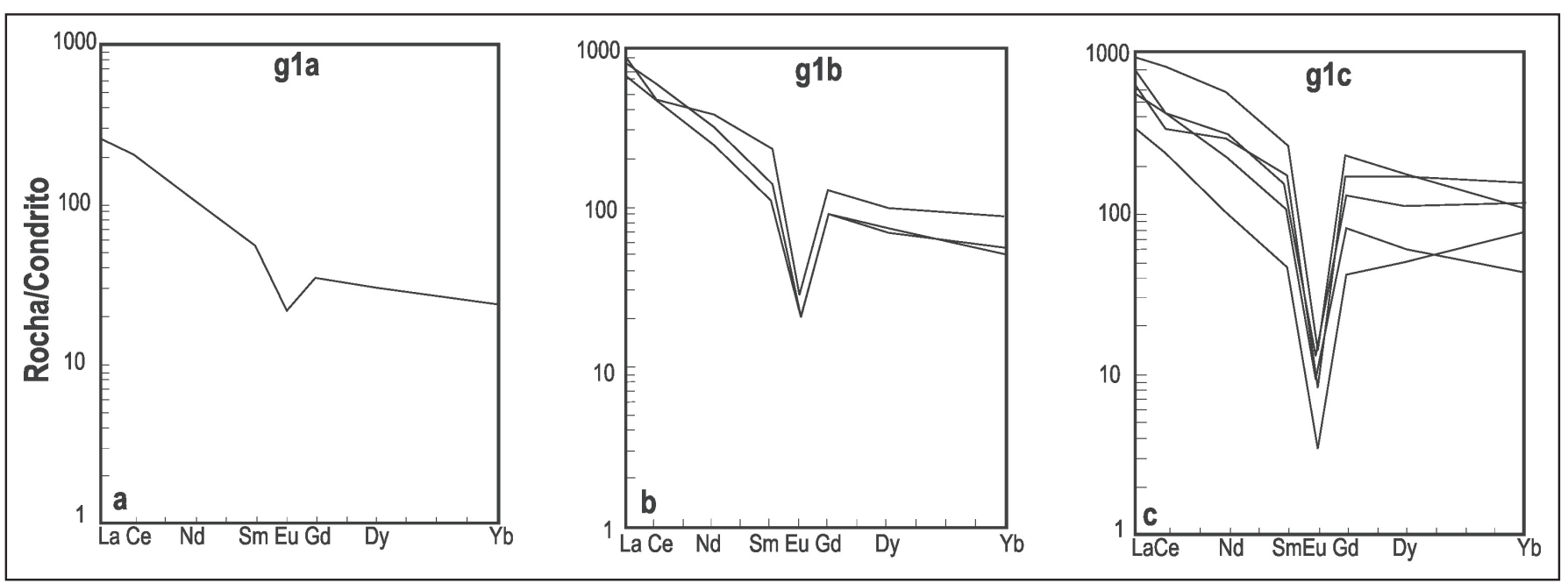

Figura 2- Evolução dos espectros de ETR na suite g1.

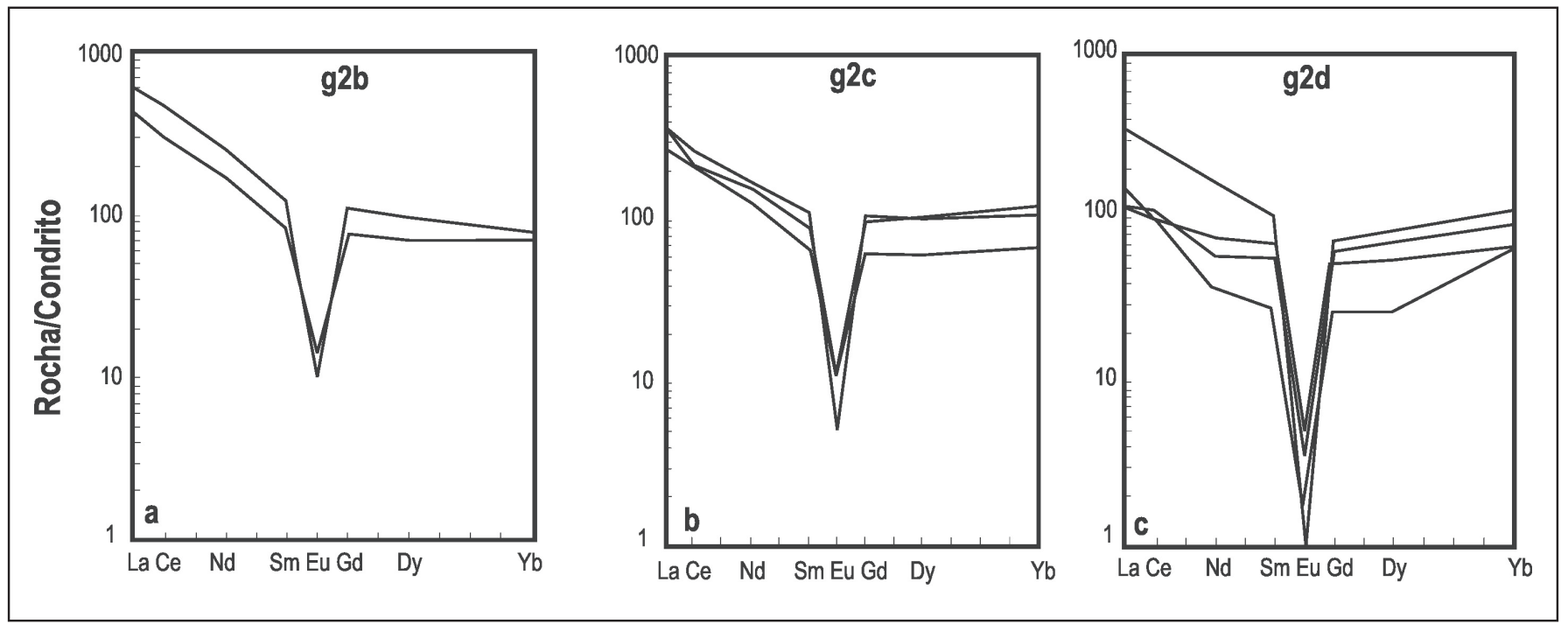

Figura 3 - Evolução dos espectros de ETR na suite g2.

mostram pequeno enriquecimento nesse processo (Bilal 1991). Os ETRL apresentam enriquecimento de 300 a 600 vezes, localizadamente chegando a 1000 vezes, o observado em condrito, enquanto o enriquecimento dos ETRP varia entre 30 e 40 vezes o condrito (figura 4 ).

Em todos os casos estudados, o comportamento dos ETR nas diferentes fácies é compatível com uma evolução magmática por cristalização fracionada.

Na suíte g1, os ETR apresentam caráter incompatível em g1a, com sua saturação sendo atingida na fácies g1b, quando se tem a cristalização de allanita e de apatitas zonadas, cujas bordas são enriquecidas em ETR (Botelho 1992, Teixeira 2002). Em g1c, há o desaparecimento da apatita e allanita enquanto a monazita, que já era encontrada em granitos g1b mais evoluídos, se torna o principal portador de ETRL (Teixeira \& Botelho 2002).

$\mathrm{Na}$ suíte g2, a saturação em ETR ocorreu logo no início do processo, quando houve a precipitação de allanita e apatita rica em ETR. Esses minerais não são mais encontrados na fácies g2d, onde a monazita passa a ser o principal portador dos ETRL (Botelho 1992, Teixeira \& Botelho 2002). A diminuição no conteúdo dos ETRL com a evolução magmática se reflete na pequena quantidade de monazita encontrada na fácies g2d.
No MSD, constata-se uma pequena diminuição na razão $(\mathrm{La} / \mathrm{Yb})_{\mathrm{N}}$ entre a Fácies de Borda e a Fácies Principal, de 13,3 para 12,5 , devido ao papel moderado da monazita no fracionamento dos ETRL e a um caráter incompatível dos ETRP entre essas duas fácies. Na fácies porfirítica, essa razão é mais elevada, entre 15 e 16, o que foi atribuído à cristalização tardia de allanita e ao desaparecimento da titanita (Bilal 1991).

Mudanças nos padrões de ETR normalizados a condrito durante a alteração hidrotermal O estudo do comportamento geoquímico de ETR durante alteração hidrotermal foi feito em amostras de fácies g1 e g2 do Maciço Pedra Branca, onde foi encontrada a maior variação faciológica entre os maciços da SPP, e do Maciço Serra Dourada, que é o maciço mais importante na SPT. Os maciços estudados apresentam importantes zonas de alteração hidrotermal onde houve o desenvolvimento de greisens, albititos e biotititos. Nessas regiões, é possível observar o contato entre a zona metassomatizada e o granito, o que permitiu o estudo das variações composicionais dos ETR devidas ao evento hidrotermal.

Para visualizar a mobilidade dos ETR, foram construídos dois diagramas com os dados químicos de rocha listados na ta- 
bela 1: i) padrões de ETR normalizados a condrito das amostras alteradas e amostra de referência e ii) padrões de ETR das amostras alteradas normalizados à amostra de referência.

\section{MACIÇO PEDRA BRANCA - SUBPROVÍNCIA PARANÃ}

Fácies g1b As amostras de granito g1b alterado foram coletadas no ponto PB198, em zona greisenizada de borda, enquanto o granito inalterado, tomado como amostra de referência, foi coletado no ponto $\mathrm{PB} 45$, em zona central não hidrotermalizada. A amostra de referência é um biotita granito com alguma cloritização da biotita, com zircão, apatita e allanita como acessórios. A amostra PB198A é um quartzo - fengita greisen mineralizado em cassiterita, com zircão, fluorita, bastnaesita e xenotima como acessórios. A amostra PB198B é semelhante à PB198A, com zircão, fluorita e monazita como acessórios.

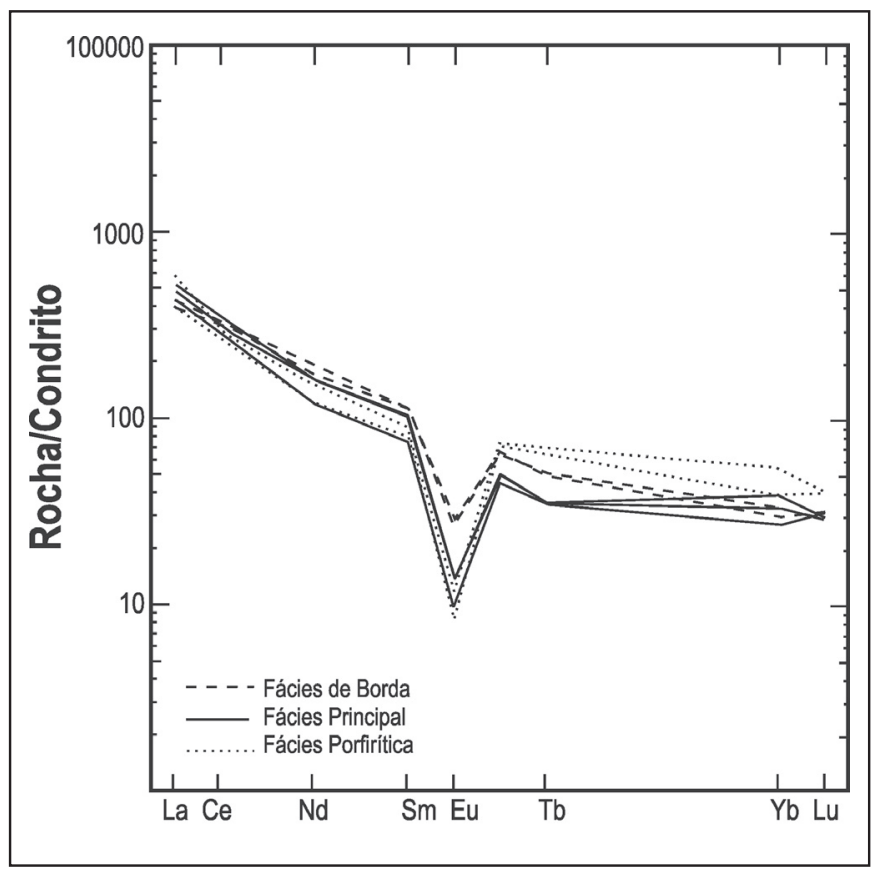

Figura 4 - Evolução dos espectros de ETR no Maciço Serra Dourada (Bilal 1991).
A PB198C é um granito greisenizado, com substituição total da biotita e parcial dos feldspatos por muscovita, de allanita por bastnaesita e neoformação de fluorita, monazita, xenotima e oxifluoreto de ETR - (ETROF). A amostra PB198D é um siderofilita - quartzo greisen mineralizado em cassiterita com fluorita e zircão como acessórios.

No ponto PB198, os ETR apresentam um comportamento complexo durante a alteração hidrotermal (figura 5). As amostras PB198A e PB198D não mostram variação significativa dos ETR em relação ao granito, embora este último tenda a ser mais rico nesses elementos. PB198C possui conteúdo em ETRL idêntico ao do granito, sendo fortemente empobrecida nos ETRP, de 6 a 9 vezes, enquanto PB198B é empobrecida em todos os ETR em relação ao granito, com este empobrecimento mais pronunciado para os ETRP, ou seja, de 8 a 9 vezes, para os ETRL e de 10 a 20 vezes para os ETRP (figura $5 b$ ). Este comportamento dos ETR se reflete na razão $(\mathrm{La} / \mathrm{Yb})_{\mathrm{N}}$, que é de 13 em PB45; 30 em PB198B e 60 em PB198C.

Fácies g1c As amostras representativas de greisenização da fácies g1c foram coletadas no ponto PB05, localizado na principal zona mineralizada do Maciço Pedra Branca, denominada de Faixa Placha e formada por greisens de fratura. PB05F é um biotita granito com alguma sericitização do feldspato, apresentando zircão e fluorita como acessórios; PB05G representa granito greisenizado com substituição total da biotita e parcial do feldspato por mica branca, com zircão, torita e fluorita como acessórios e PB05H é um quartzo - siderofilita greisen mineralizado em cassiterita, com zircão e torita como acessórios.

Não há variação significativa na forma do padrão e na razão $(\mathrm{La} / \mathrm{Yb})_{\mathrm{N}}$ entre o granito e as rochas hidrotermalizadas, cujos valores são 13, no granito, 12, no granito greisenizado e 11, no greisen (figura 6a). Os padrões de ETR normalizados a condrito do granito e do granito greisenizado se sobrepõem, com o granito greisenizado apresentando pequeno enriquecimento em $\mathrm{Gd}$ e Dy e pequeno empobrecimento em Ce e Nd em relação ao granito. Em contrapartida, o greisen mostra forte empobrecimento dos ETR, de 8 a 9 vezes, em relação ao granito (figura $6 b$ ).

Fácies g2d As amostras que representam a greisenização do granito g2d foram coletadas no ponto PB197, também localizado na Faixa Placha, cujas características são as seguintes: PB197A - biotita granito com alguma alteração de biotita e plagioclásio
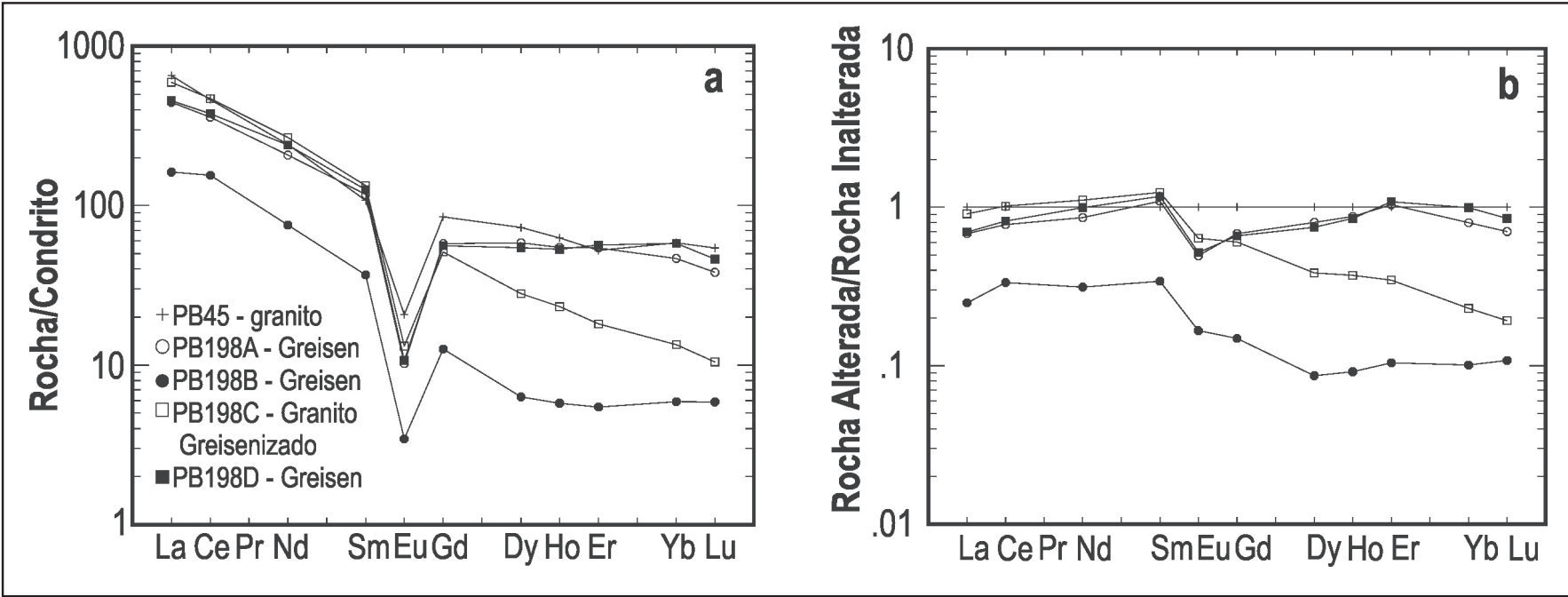

Figura 5 - a) padrões de ETR normalizados a condrito de amostras coletadas no ponto PB 198, b) padrões de ETR das amostras alteradas normalizados à amostra de referência. 
para mica branca e apresentando fluorita e zircão como acessórios; PB197B - granito greisenizado (substituição parcial da biotita e feldspato por mica branca) mineralizado em cassiterita, com zircão, fluorita e torita como acessórios; PB197C - quartzo - siderofilita greisen mineralizado em cassiterita, com zircão, monazita, torita e fluorita como acessórios.

Há um empobrecimento em ETR entre o granito e as rochas alteradas hidrotermalmente, principalmente no granito greisenizado (figura 7). Esse empobrecimento é de 3 a 6 vezes para os ETRL, tanto entre o granito e o granito greisenizado quanto entre o granito greisenizado e o greisen, 5 a 7 vezes para os ETRP, entre o granito e o greisen, e de 8 e 9 vezes para os ETRP, entre o granito e o granito greisenizado. A razão $(\mathrm{La} / \mathrm{Yb})_{\mathrm{N}}$ aumenta de 3 , no granito, para 12 , no granito greisenizado e para 6 , no greisen.

Discussões Todas as amostras estudadas da SPP, tanto da suíte g1 quanto da suíte g2, mostram diminuição no conteúdo de ETR entre granito e greisen. Isto, associado às variações na forma dos padrões, às mudanças na razão $(\mathrm{La} / \mathrm{Yb})_{\mathrm{N}}$ e às variações nas taxas de empobrecimento para o ETRL e ETRP, sugere a lixiviação dos ETR durante a alteração hidrotermal. A presença de minerais secundários, como fluorita, bastnaesita e oxifluoreto de ETR nos greisens, indica a presença de $\mathrm{F}$ e $\mathrm{CO}_{2}$ no fluido hidrotermal. Esses elementos formam complexos com os ETR, do tipo fluoretos ou carbonatos, que podem então ser lixiviados durante o evento hidrotermal (Kosterin 1959, Alderton et al. 1980, Leroy \& Turpin 1988 e Wood 1990). A lixiviação preferencial dos ETRP em relação aos ETRL está em acordo com observações de Baker (1985) que constataram a complexação preferencial desses elementos com o $\mathrm{F}$ em relação aos ETRL, enquanto Leroy \& Turpin (1988) e Gramaccioli et al. (1999) mostraram que a estabilidade dos complexos de ETR aumenta do La ao Lu.

Alderton et al. (1980) e Leroy \& Turpin (1988) constataram que os ETR são pouco móveis durante sericitização em presença de fluidos aquosos oxidantes e com baixo conteúdo em sais. As amostras PB198A e PB198D, onde os ETR são pouco móveis, são greisens com cassiterita isto é, foram submetidas

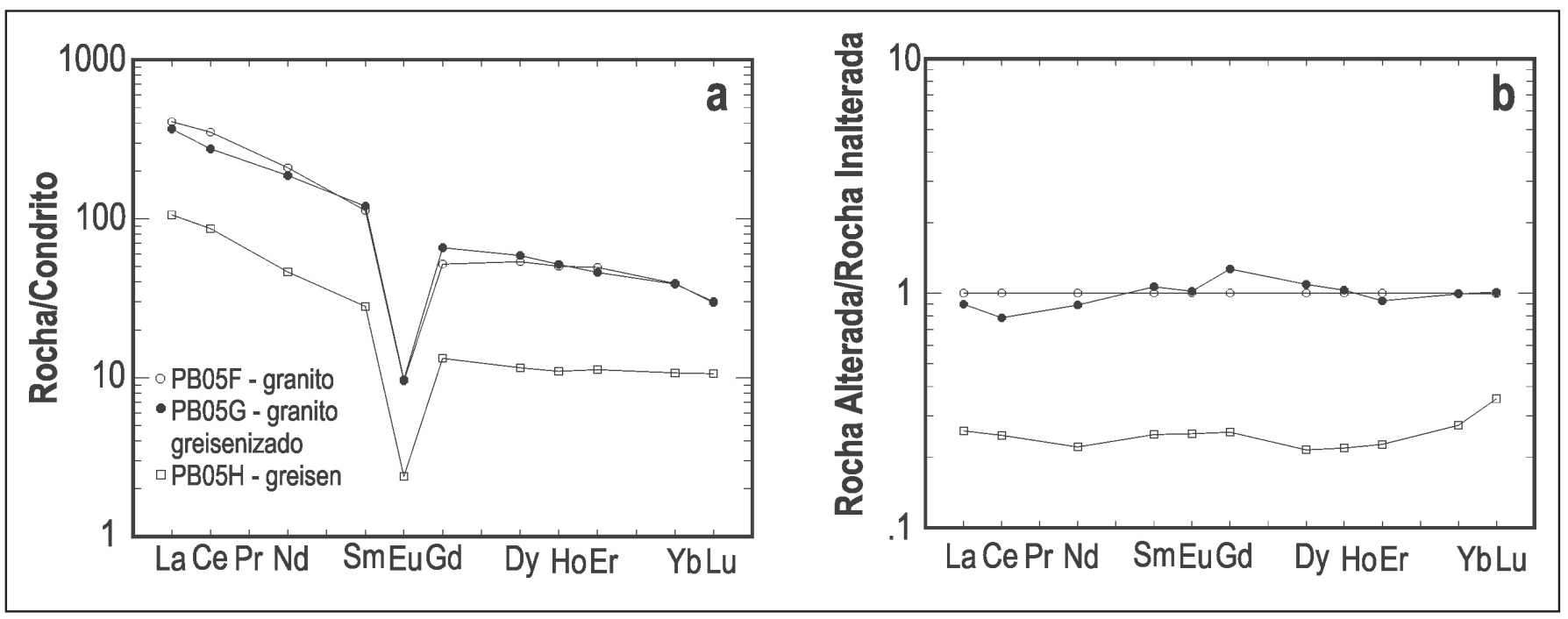

Figura 6-a) padrões de ETR normalizados a condrito de amostras coletadas no ponto PB 05, b) padrões de ETR das amostras alteradas normalizados à amostra de referência.

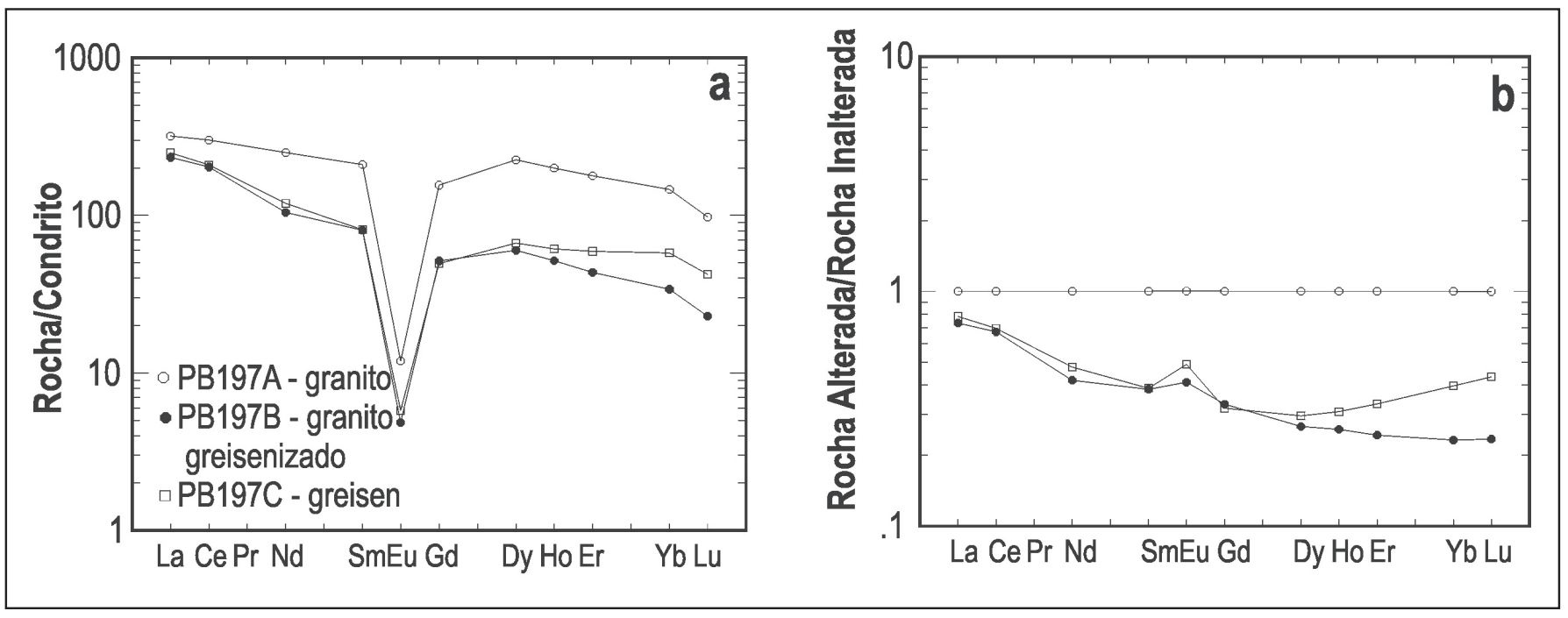

Figura 7 - a) padrões de ETR normalizados a condrito de amostras coletadas no ponto PB 197, b) padrões de ETR das amostras alteradas normalizados à amostra de referência. 
a um processo claramente oxidante, o que favoreceu a pouca mobilidade dos ETR. Entretanto, essas amostras possuem fluorita e bastnaesita como minerais neoformados, o que sugere a presença de $\mathrm{Fe}\left(\mathrm{CO}_{3}\right)^{2-}$ no fluido, o que, por sua vez, favoreceria a lixiviação dos ETR. Presume-se que os ETR foram liberados dos seus sítios originais nos minerais pela atuação de fluidos ricos em F, mas se precipitaram imediatamente após liberação, como fases secundárias, não afetando de forma significativa no conteúdo dos ETR em rocha.

\section{MACIÇO SERRA DOURADA - SUBPROVÍNCIA TOCAN- TINS}

Fácies de Borda As amostras representativas da alteração da Fácies de Borda foram coletadas no ponto SD9, localizado na região do Garimpo de Estanho do Cruzeiro. Destas, a SD9A é um biotita granito deformado e recristalizado, apresentando início de saussuritização do plagioclásio e cloritização da biotita, com zircão, titanita, allanita e fluorita como acessórios. SD9B, muito semelhante a SD9A, difere por ser mais rica em biotita, com allanita, fluorita, zircão e titanita como acessórios e SD9C é um biotitito constituído por biotita, (entre 50 e $60 \%$ da rocha), quartzo, plagioclásio, microclínio e hornblenda, apresentando zircão, fluorita e apatita, além de allanita, em proporção de até $1 \%$ da rocha, como acessórios.

Não há variação significativa no conteúdo de ETR, entre o granito e o granito biotitizado (figura 8), apenas um pequeno empobrecimento $(\approx 1 \mathrm{vez})$ dos ETRL, enquanto o biotitito mostra enriquecimento de aproximadamente duas vezes para os ETRL e uma vez para o Tb (figura 8). Não se constata variação significativa na forma dos padrões, caracterizada por curvas descendentes, com pronunciada anomalia negativa em Eu, nem no grau de fracionamento entre o granito e as rochas alteradas hidrotermalmente, evidenciado pela razão $(\mathrm{La} / \mathrm{Tb})$, igual a 12,5 no granito, a 10 no granito alterado e a 13 no biotitito.

Fácies Principal As amostras da Fácies Principal, alteradas hidrotermalmente, foram coletadas no ponto SD24, enquanto o granito inalterado foi coletado no ponto PE-6, ambos localizados na região do depósito de estanho do Buriti. A amostra PE-6 é um biotita granito, com zircão e allanita como acessórios. SD24A é um albitito, constituído de albita, quartzo, biotita e algum microclínio, com zircão, bastnaesita e monazita como acessórios;
SD24E é um biotitito, constituído por biotita (aproximadamente $50 \%$ da amostra), quartzo e mica branca, com até $1 \%$ de monazita como acessório, enquanto SD24G é um albitito semelhante a SD24A, apresentando zircão como acessório.

Com exceção da amostra SD24A, cujo padrão é aproximadamente plano, as demais amostras estudadas possuem padrões de ETR normalizados a condrito descendentes, com acentuada anomalia negativa em Eu (figura 9). O conteúdo em ETRL de SD24G é semelhante ao do granito, embora se constate enriquecimento $(\approx 1 \mathrm{vez})$ para os ETRP. As amostras SD24A e SD24E mostram enriquecimento, até 10 vezes, de todos ETR em relação ao granito. Mesmo as amostras SD24A e SD24G sendo de albitito, ambas diferem no enriquecimento em ETR em relação ao granito: o albitito SD24A é de 2 a 3 vezes mais rico nos ETRL e até 10 vezes mais rico nos ETRP do que o granito (figura 9), enquanto o albitito SD24G possui conteúdos de ETR semelhante aos do biotita granito (PE6) da Fácies Principal. O biotitito SD24E é, com exceção do Ce, de 1 a 3 vezes mais rico nos ETR que a amostra de referência PE6 (figura 9).

A razão $(\mathrm{La} / \mathrm{Yb})$, praticamente não varia entre o granito $(8,5)$ e o biotitito $(8,0)$, diminuindo consideravelmente durante a albitização (5,7 em SD24G e 1,5 em SD24A). Deste modo, durante a biotitização o aporte de ETR se deu de forma homogênea, com a manutenção da razão $(\mathrm{La} / \mathrm{Yb})_{N}$, enquanto durante a albitização houve um maior aporte dos ETRP em relação aos ETRL.

Discussões A identificação de fluorita, allanita e fluorcarbonatos de ETR nas amostras das fácies de borda e principal do MSD sugere a presença de $\mathrm{F}$ e $\mathrm{CO}_{2}$, no fluido hidrotermal. Inicialmente, o fluido deve ter lixiviado os ETR do granito, transportando-os como fluoretos e carbonatos. Entretanto, a ausência de topázio, a pequena quantidade de fluorita e a composição química da biotita encontrada nos biotititos do MSD (Bilal 1991) sugerem que fluidos atuantes neste maciço eram mais pobres em $\mathrm{F}$ do que aqueles atuantes na SPP, de modo que, quando houve a precipitação de fluorita no biotitito, ainda que em pequenas quantidades, a diminuição nos conteúdos em F provocou a desestabilização dos complexos e precipitação de allanita e bastnaesita. A manutenção das formas dos padrões e as razões $(\mathrm{La} / \mathrm{Tb})_{\mathrm{N}}$ semelhantes entre o granito e o biotitito mostram que não houve fracionamento dos ETR nesse processo.

O enriquecimento em ETR nos albititos em relação aos gra-

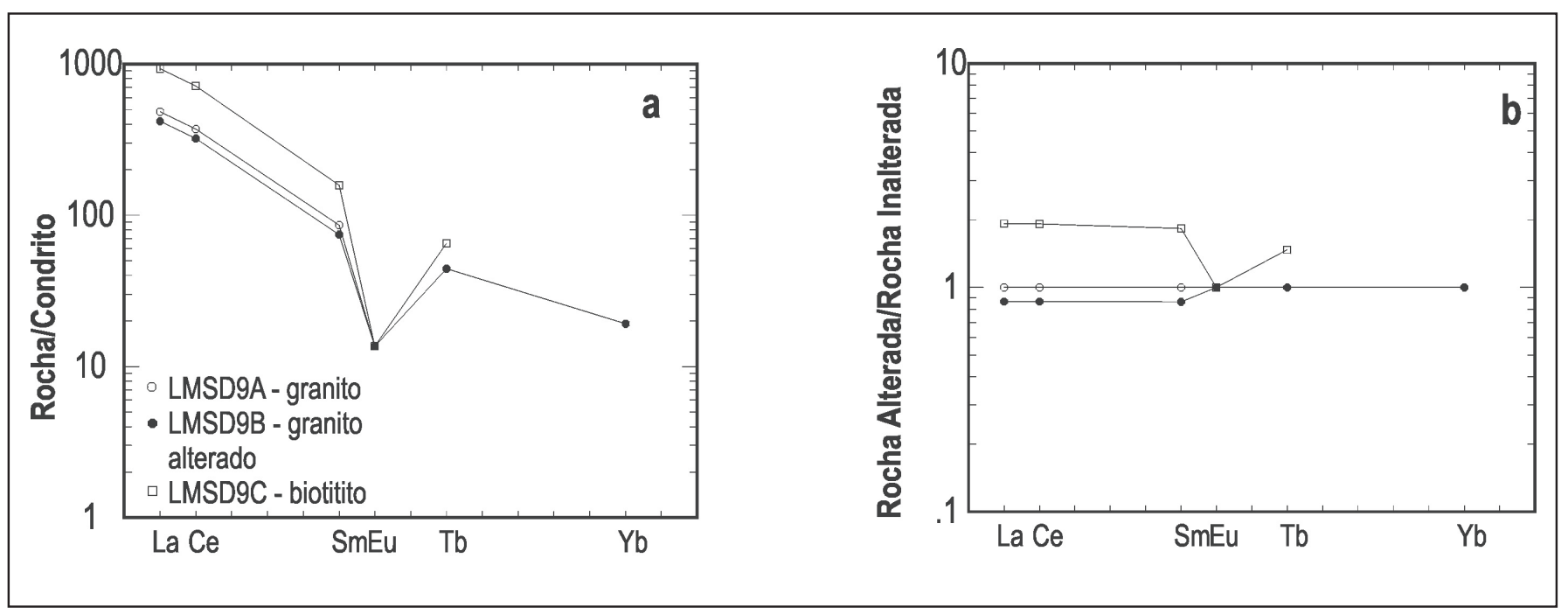

Figura 8 - a) padrões de ETR normalizados a condrito de amostras coletadas no ponto SD9, b) padrões de ETR das amostras alteradas normalizados à amostra de referência. 


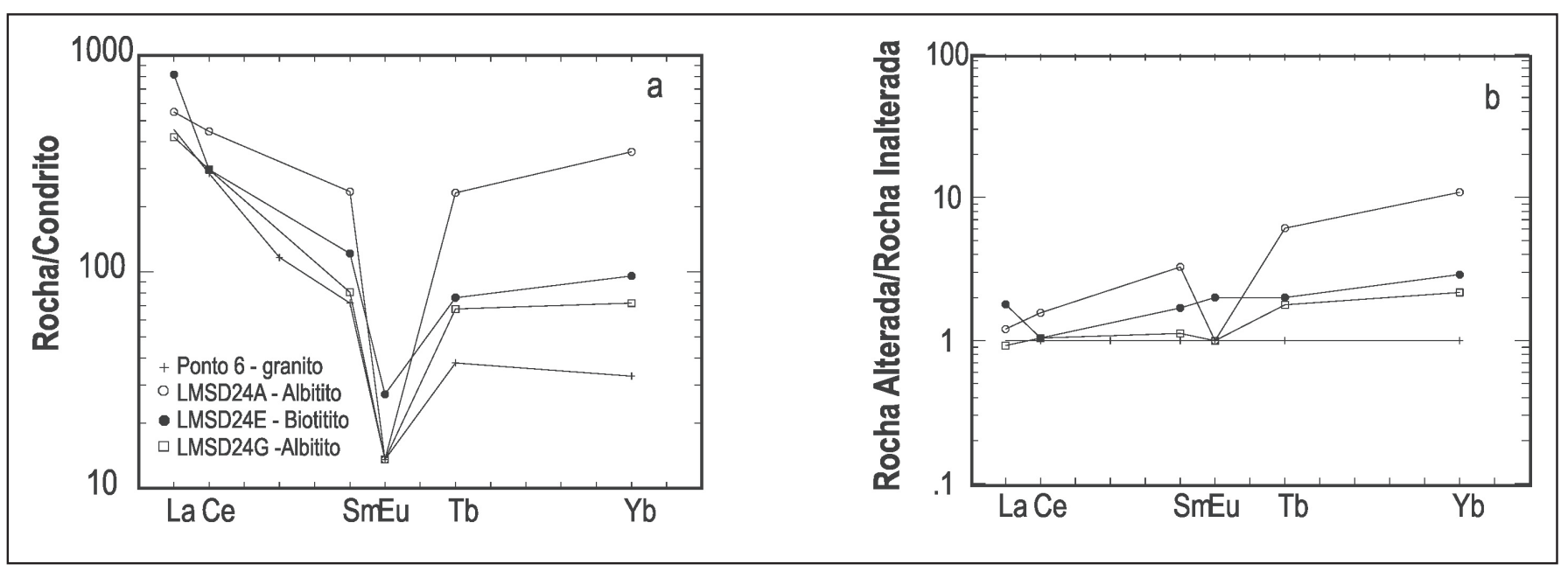

Figura 9-a) padrões de ETR normalizados a condrito de amostras coletadas no ponto SD24, b) padrões de ETR das amostras alteradas normalizados à amostra de referência.

nitos foi atribuído ao enriquecimento residual dos ETR, pois fluidos alcalinos, como os atuantes no MSD, tendem a lixiviar elementos como $\mathrm{Si}$, mas praticamente não mobilizam os ETR, que tendem a permanecer e se enriquecer no sistema.

\section{Minerais Responsáveis pelos Elementos Terras Raras em Rocha \\ MACIÇO PEDRA BRANCA (MPB) - SUBPROVÍNCIA PARA- $N \tilde{A}$}

Fácies glb Há uma pequena diminuição na quantidade de zircão entre o granito e as rochas hidrotermalizadas (tabela 3) sugerindo que, mesmo se tratando de mineral resistato, o zircão foi parcialmente consumido durante a greisenização. $\mathrm{O}$ ácido fluorídrico (HF) é o único ácido capaz de dissolver, embora com dificuldade, o zircão (Rubin et al. 1993). A presença de fluorita, bastnaesita e oxifluoreto de ETR nos granitos greisenizados e greisens desenvolvidos sobre a fácies $\mathrm{g} 1 \mathrm{~b}$ mostra que o $\mathrm{F}$ era um elemento comum no fluido hidrotermal. Como esse fluido também era aquoso (Botelho 1992), pode ter havido a formação de HF que levaria à destruição parcial do zircão durante o hidrotermalismo. Elementos comumente considerados muito pouco móveis, como $\mathrm{Zr}$ e ETR, podem ser transportados para fora do sistema na forma de fluoretos (Kosterin 1953, Alderton et al. 1980; Baker 1985; Pointer et al. 1988; Rubin et al. 1993; Aja et al. 1996 entre outros). Por ser pobre nos ETR (tabela 2), a diminuição na quantidade de zircão durante a greisenização não afetou o conteúdo dos ETR em rocha.

Durante a greisenização do granito g1b houve consumo de allanita e apatita e neoformação de monazita, bastnaesita e oxifluoretos de ETR, que passam a ser os portadores de ETRL em rocha. Praticamente, não se constata variação no conteúdo dos ETR entre o granito (PB45), granito greisenizado (PB198C) e os greisens das amostras PB198A e PB198D (figura 5). Em termos absolutos há diminuição na quantidade de minerais portadores de ETRL entre o granito e as rochas hidrotermalizadas (tabela 3), mas esta diminuição é compensada pela presença, nos greisens, de minerais mais ricos em ETRL que a allanita e a apatita encontradas no granito (tabela 2). A quantidade de monazita, bastnaesita e oxifluoretos de ETR nas rochas alteradas (exceto amostra PB198B) não varia, permanecendo em torno de $0,1 \%$.

O greisen da amostra PB198B é empobrecido em ETRL em relação ao granito (figura 5). Nesta amostra, a allanita foi substituída por monazita como principal portador de ETRL, mas este mineral ocorre em quantidades inferiores àquelas observadas nos outros greisens $(0,044 \%$ em PB198B contra aproximadamente $0,1 \%$ nas demais amostras - tabela 3 .

Fácies g1c Em amostras coletadas no ponto PB05, foi constatada a presença de zircão, torita e monazita como acessórios (tabela 3). Embora haja uma pequena diminuição na quantidade, os conteúdos de monazita e zircão são semelhantes entre o granito $(0,1$ e $0,05 \%$ respectivamente) e o granito greisenizado $(0,089$ e $0,045 \%$ respectivamente) e baixam para $0,026 \%$ e $0,027 \%$ respectivamente no greisen. A atuação de fluidos hidrotermais ricos em $\mathrm{F}$ e com algum $\mathrm{CO}_{2}$ promoveram a lixiviação do $\mathrm{Zr}$ e dos ETR, com conseqüente diminuição na quantidade de minerais portadores desses elementos durante a alteração hidrotermal. O mesmo foi constatado com relação à torita $(0,019 \%$ no granito, $0,016 \%$ no granito greisenizado e apenas $0,007 \%$ no greisen), sugerindo que este mineral foi parcialmente destruído durante a greisenização.

Fácies g2d Os minerais acessórios encontrados no ponto PB198 foram o zircão, a monazita e a torita. Embora não exista variação significativa na quantidade de zircão entre o granito e o granito greisenizado, 0,035 e $0,034 \%$ respectivamente, constata-se diminuição da concentração deste mineral entre o granito e o greisen, 0,035 e $0,029 \%$ respectivamente (tabela 3 ). A suíte g2 é mais rica em F que a g1 (Botelho 1992), de modo que o zircão foi parcialmente consumido durante a greisenização pela atuação de fluidos ricos em $\mathrm{F}$, com lixiviação do $\mathrm{Zr}$ na forma de fluoretos.

Há diminuição na quantidade de monazita entre o granito e as rochas hidrotermalizadas, com conteúdo nesse mineral semelhante entre as amostras PB197B e PB197C (tabela 3).

Não há variação significativa na quantidade de torita durante a alteração hidrotermal, cuja concentração é semelhante no granito, $0,014 \%$, no granito greisenizado, $0016 \%$, e no greisen, $0,014 \%$ (tabela 3 ).

Discussões Em todas as fácies da SPP estudadas, uma parte significativa dos ETRP em rocha se deve principalmente aos minerais portadores de ETRL. Entretanto, estes, assim como o zircão e torita, não explicam totalmente a presença dos ETRP. É provável que parte dos ETRP se deva à presença de xenotima $\left(\mathrm{YPO}_{4}\right)$, identificada em várias amostras de granito e granito greisenizado de outras regiões da SPP. Embora este mineral não tenha sido identificado nas amostras estudadas, estimou-se 
Tabela 3 - Conteúdo dos minerais acessórios em rocha (resultado dos cálculos).

\begin{tabular}{|c|c|}
\hline \multicolumn{2}{|r|}{ Maciço Pedra Branca - Subprovíncia Paranã } \\
\hline \multirow{5}{*}{ Fácies g1b } & PB45 - zircão - 0,0848\%; allanita $-0,496 \%$; xenotima $-0,025 \%$ \\
\hline & PB198A - zircão - 0,066\%; bastnaesita - 0,092\%; xenotima - 0,025\% \\
\hline & PB198B - zircão - 0,065\%; monazita - 0,044\% \\
\hline & $\begin{array}{l}\text { PB198C - zircão - 0,067\%; monazita - 0,031\%; bastnaesita - 0,069\%; oxifluoreto de ETR - 0,029\%; xenotima - } \\
0,000165 \%\end{array}$ \\
\hline & PB198D - zircão - 0,079\%; monazita - 0,11\%, xenotima - 0,00219\% \\
\hline \multirow[t]{3}{*}{ Fácies g1c } & PB05F-zircão - 0,051\%; monazita - 0,099\%, torita $-0,019 \%$, xenotima $-0,0091 \%$ \\
\hline & PB05G - Zircão - 0,0436\%; monazita $-0,089 \%$, torita $-0,0159 \%$; xenotima $-0,0158 \%$. \\
\hline & PB05H - zircão - $0,027 \%$; monazita $-0,026 \%$; torita $-0,0067 \%$; xenotima $-0,0024 \%$ \\
\hline \multirow[t]{3}{*}{ Fácies g2d } & PB197A - Zircão - 0,035\%; monazita $-0,099 \%$, torita $-0,016 \%$; xenotima $-0,092 \%$ \\
\hline & PB197B - zircão - $0,034 \%$; monazita $-0,058 \%$, torita $-0,016 \%$, xenotima $-0,015 \%$ \\
\hline & PB197C - zircão - $0,029 \%$, monazita $-0,062 \%$, torita $-0,014 \%$, xenotima $-0,022 \%$. \\
\hline \multicolumn{2}{|r|}{ Maciço Serra Dourada - Subprovíncia Tocantins } \\
\hline \multirow{3}{*}{ Fácies de Borda } & SD9A - zircão - $0,0439 \%$; allanita $-0,394 \%$; xenotima $-0,00658 \%$ \\
\hline & SD9B - zircão - 0,0498\%; allanita - 0,3416\%; xenotima $-0,00849 \%$. \\
\hline & SD9C - Zircão - 0,0495\%; allanita - 0,624\% \\
\hline \multirow[t]{4}{*}{ Fácies Principal } & PE-6 - zircão - 0,045\%; allanita - 0,354\%; xenotima - 0,041\%. \\
\hline & SD24A - zircão - $0,0349 \%$; monazita $-0,0708 \%$; bastnaesita $-0,086 \%$; xenotima $-0,232 \%$ \\
\hline & SD24E - zircão - 0,0374\%; monazita - 0,119\%; xenotima - 0,0619\%. \\
\hline & SD24G - zircão - 0,03399\%; monazita - $0,0949 \%$; xenotima $-0,045 \%$ \\
\hline
\end{tabular}

quantidades de xenotima que seriam responsáveis pela presença dos ETRP em rocha não justificadas pelos minerais citados anteriormente. Não se constata variação significativa na quantidade calculada de xenotima entre o granito (PB45 - 0,025\%) e as amostras PB198A (0,025\%) e PB198D (0,022\%) (tabela 3). As amostras PB198B e PB198C são empobrecidas nos ETRP em relação ao granito, o que se reflete na pequena quantidade de xenotima na amostra PB198C $(0,002 \%)$ e na sua ausência na amostra PB198B (tabela 3).

No ponto PB05, a maior concentração calculada de xenotima no granito greisenizado em relação ao granito (tabela 3) é justificada pela maior quantidade de alguns ETRP (Gd e Dy) no primeiro (tabela 1). O baixo conteúdo desse mineral no greisen é resultado da lixiviação dos ETR durante o hidrotermalismo.

$\mathrm{Na}$ fácies g2d, constata-se diminuição significativa no conteúdo calculado deste mineral entre o granito $(0,09 \%)$, o granito greisenizado $(0,015 \%)$ e o greisen $(0,02 \%)$, com a amostra PB197B apresentando ainda menor quantidade de xenotima que PB197C (tabela 3). Isto reflete a diminuição dos ETRP durante a alteração hidrotermal, com empobrecimento nesses elementos mais pronunciado no granito greisenizado que no greisen.

MACIÇO SERRA DOURADA (MSD) - SUBPROVÍNCIA TOCANTINS

Fácies de Borda Não há variação significativa na quantidade de zircão entre o granito (SD9A), o granito alterado (SD9B) e o biotitito (SD9C) (tabela 3), não havendo destruição desse mineral durante a biotitização. No MSD, a alteração hidrotermal possui tendência alcalina, originando albititos e biotititos, o que aumenta a estabilidade do zircão (Speer 1982a). A ausência de topázio e a pequena quantidade de fluorita nos albititos e biotititos sugerem que, no MSD, o fluido era mais pobre em F que aquele atuante na SPP, o que diminuiria a sua eficácia na quebra do zircão e transporte de Zr pelo mesmo.

Em todas as amostras foi constatada a presença de allanita, mas sua quantidade aumenta significativamente entre o granito e o biotitito (tabela 3), o que está em acordo com os dados de química de rocha (tabela 1 e figura 8).

Fácies Principal As rochas hidrotermais encontradas no ponto SD24 são enriquecidas em ETR, principalmente ETRP, em relação ao granito (tabela 1 e figura 9).

A quantidade de zircão diminui entre o granito (PE-6) e as rochas hidrotermalizadas do ponto SD24, mas esta não é significativa (tabela 3), mostrando que, no MSD, o zircão não foi tão afetado pelo hidrotermalismo quanto no Maciço Pedra Branca. Aparentemente, este fato está relacionado à composição do fluido hidrotermal, que é mais alcalino, e mais pobre em F, o que aumentaria a estabilidade do zircão.

A allanita é o principal portador de ETRL no granito, não sendo mais encontrada nos albititos e biotititos, onde a monazita e, mais raramente, a bastnaesita passam a ser os principais 
concentradores de ETRL (tabela 3).

Em termos absolutos, há diminuição na quantidade de minerais portadores de ETRL entre o granito e as rochas hidrotermalizadas, o que se deve ao fato de a allanita ter menor conteúdo em ETR que a monazita e a bastnaesita (tabela 2).

Discussões Embora allanita, monazita, bastnaesita e, em menor quantidade, zircão respondam por uma porção significativa dos ETRP nas fácies principal e de borda do MSD, esses minerais não são responsáveis por todo o conteúdo desses elementos, sendo provável a presença de alguma xenotima, que foi constatada em aluviões do MSD.

$\mathrm{Na}$ fácies principal, não há variação significativa na quantidade de xenotima entre o granito e o granito alterado, não sendo necessário estimar a sua presença no biotitito (tabela 3 ). $\mathrm{Na}$ fácies de borda há um aumento significativo na quantidade de xenotima entre o granito e as rochas hidrotermalizadas, o que reflete o enriquecimento em ETRP observado durante a alteração hidrotermal. Mesmo os ETRP tendendo a formar complexos mais estáveis que os ETRL, eles devem ter se precipitado quando da formação de fluorita, que empobreceu o fluido em F, provocando a desestabilização dos complexos de ETR, inclusive complexos com ETRP, com precipitação desses elementos como fases neoformadas.

CONCLUSÕES Em todos os maciços estudados, o comportamento dos ETR durante a evolução magmática é compatível com uma evolução por cristalização fracionada, onde os minerais acessórios têm um papel preponderante no controle das va- riações dos ETR em rocha.

No MPB, ocorre diminuição na quantidade de ETR em rocha entre o granito e as rochas alteradas hidrotermalmente, enquanto no MSD ocorre aumento na quantidade de ETR com a alteração hidrotermal. Este comportamento discrepante dos ETR durante o hidrotermalismo deve-se às diferenças composicionais do fluido hidrotermal que é mais ácido e rico em $\mathrm{F}$ na região da SPP, originando basicamente greisens e levando à mobilização e lixiviação dos ETR, e mais alcalino e pobre em F no MSD, formando basicamente albititos, de modo que, mesmo sendo disponibilizados dos seus sítios originais nos minerais, os ETR tendem a permanecer no sistema.

Em todos os maciços estudados, allanita, monazita, bastnaesita e oxifluoretos de ETR são os principais portadores dos ETRL em rocha. Além dos ETRL, esses minerais são também responsáveis por uma parte significativa dos ETRP. Por outro lado, os ETRP que não são provenientes dos minerais portadores de ETRL são encontrados na xenotima e na torita. O zircão, embora seja o acessório mais comum, praticamente não influencia nas concentrações e nos padrões de ETR em rocha.

Agradecimentos Ao CNPq, pelo financiamento à pesquisa (processo 14702/1998-6 e 475193-4) bem como aos professores Márcia A. Moura, José A. Brod, Silvio R. F. Vlach e Herbet Conceição pelas correções e sugestões para a Tese de Doutorado de L. M. Teixeira e aos técnicos Nelson Fava e Onésio R. Nunes Filho, do IG-UnB, e Christian Gilles e Olivier Rouer, do BRGM, pelo auxílio na aquisição dos dados de Microssonda Eletrônica.

\section{Referências}

Aja S.U., Wood S.A., Williams-Jones A.E. 1996. The aqueous geochemistry of $\mathrm{Zr}$ and the solubility of some Zrbearing minerals. App. Geochem., 10:603-620.

Alderton D.H.M., Pearce J.A., Potts P.J. 1980. Rare earth element mobility during granite alteration: evidence from southwest England. Earth Planet. Sci. Let., 49:149 - 165

Alvarenga C.J.S., Botelho N.F., Dardenne M.A., Campos J.E.G., Martins F.A.L., Menezes P.R., Moura M.A. 2000. Magmatic and stratigraphic evolution of a Paleo/Mesoproterozoic syn-rift to post-rift basin: example of the Araí Basin, Brazil. In: International Geological Congress, 31, Rio de Janeiro, Abstracts, CD-Rom.

Åmli R. \& Griffin W.L. 1975. Microprobe analysis of REE minerals using empirical correction factors. Am. Min., 60:599-606.

Baker J.H. 1985. Rare earth and other trace element mobility accompanying albitization in a Proterozoic granite, W. Bergslagen, Sweden. Min. Mag., 49:107-115.

Bau M. 1991. Rare-earth element mobility during hydrothermal and metamorphic fluid-rock interaction and the significance of the oxidation state of europium. Chem. Geol., 93:219-230.

Bilal E. 1991. Étude de deux massifs de la province granitique stannifère de l'Etat de Goiás (Brésil) et des formations métasomatiques associées aux minéralisations en Sn et Be. Thèse de Doctorat, École des Mines de Saint-Etienne, 382p.

Bilal E., Moute J., Botelho N.F., Marini O.J., Andrade G.F. 1997. Geochemistry of two Proterozoic A type granites of Goiás State, Brazil: possible links with rapakivi series. Anuário da Acad. Bras. Ciênc., 69:349-365.

Botelho N.F. 1992. Les ensembles granitiques subalcalins a peralumineux mineralisés en Sn et In de la Sousprovince Paranã. Etat de Goiás, Brèsil. Thèse de Doctorat. Université de Paris VI, 344p.

Botelho N.F., Alvarenga C.J.S., Menezes P.R., D'el Rey Silva L. J. H. 1999. Suíte Aurumina: uma suíte de granitos paleoproterozóicos, peraluminosos e sintectônicos na Faixa Brasília. In: SBG/Núcleo Centro Oeste e Minas Gerais, Simp.Geol. Centro Oeste, 7, Brasília,
Boletim de Resumos, v. 1. p. 49-49.

Cathelineau M. 1987. U-Th-REE mobility during albitization and quartz dissolution in granitoids: evidence from southeast French Massif Central. Bull. Mineral., 110:249-259.

Chang L., Howie R.A., Zussman J. 1996. Rock Forming Minerals - volume $5 B$ - Non Silicates - Sulphates, Carbonates, Phosphates and Halides. 2nd, Longma Group Limited, 383p.

Charoy B., Pollard P.J. 1989. Albite-rich, silica-depleted metasomatic rocks at Emuford, northeast Queensland: Mineralogical, geochemi$\mathrm{cal}$, and fluid inclusion constraints on hydrothermal evolution and tin mineralization. Econ.Geol., 84:1850-1874.

Deer W.A., Howie R.A., Zussman J. 1997. Rock Forming Minerals volume 1a Orthosilicates. The Geological Society, 919p.

Franz G., Andrehs G., Rhede D. 1996. Crystal chemistry of monazite and xenotime from Saxothuringian-Moldanubian metapelites, NE Bavaria, Germany. Eur. Jour. Of Min., 8:1097-1118.

Gramaccioli C.M., Diella V., Demartin F. 1999. The role of fluoride complexes in REE geochemistry and the importance of $4 f$ electrons: Some examples in minerals. Eur. Jour. Min., 11:983-992.

Hanson G.N. 1989. An approach to trace element modeling using a simple igneous system as an example. In: B.R. Lippin \& G.A. McKay (eds.) Geochemistry and Mineralogy of the Rare Earth Elements. Reviews in Mineralogy, 21, Mineralogical Society of America. pp. 79-98.

Henderson P. 1984. Rare Earth Element Geochemistry. Elsevier, 510pp. Henderson P. 1996. The rare earth elements: introduction and review. In: A.P. Jones, F.E. Wall, C.T. Williams (eds.) Rare Earth Minerals: Chemistry, Origin and Ore Deposits. Chapman \& Hall. pp.1-20.

Jefferies N.F. 1985. The disttribution of the rare earth elements within the Carnmenellis Pluton, Cornwall. Min. Mag., 49:495-504.

Kosterin A.V. 1959. The possible modes of transport of the rare earth by hydrothermal solutions. Geochemistry, 4:381-387.

Lacerda Filho J.V., Ribeiro P.S.E., Ribeiro Filho W., Dardenne M.A. 1999. Geologia e Recursos Minerais do Estado de Goiás e do Dis- 
trito Federal - Relatório do Mapa Geológico do Estado de Goiás. Goiânia, CPRM/METAGO/Unb, Escala 1:500.000. 1999.

Leroy J.L. \& Turpin L. 1988. REE, Th and U behaviour during hydrothermal and supergene processes in a granitic environment. Chem. Geol., 68:239-251.

Macambira M.J.B. 1983 Ambiente geológico e mineralizações associadas ao Granito Serra Dourada (Extremidade Meridional) - Goiás. Tese de Doutoramento, Instituto de Geociências, Universidade Federal do Pará, 132p.

Marini O.J. \& Botelho N.F. 1986. A Província de Granitos Estaníferos de Goiás. Rev. Bras. Geoc., 16:119-131.

Marini O.J., Fuck R.A., Dardenne M.A., Faria A. 1977. Contribuição à geologia do Pré - Cambriano da porção central de Goiás. Rev. Bras. Geoc., 7:304-324.

Pereira A.B. 2001. Caracterização dos Granitos e Pegmatitos Peraluminosos, Mineralizados em Sn-Ta, de Monte Alegre de Goiás. Dissertação de Mestrado, Instituto de Geociências, Universidade de Brasília, $157 \mathrm{p}$.

Pimentel M.M., Heaman L., Fuck R.A., Marini O.J. 1991. U-Pb zircon geochronology of Precambrian tin bearing continental-type acid magmatism in Central Brazil. Precam. Res., 52:321-335.

Pointer C.M., Ashworth J.R., Ixer R.A. 1988. The zircon-thorite mineral group in metasomatized granite, Ririwai, Nigeria. 2 - Zoning, alteration and exsolution in zircon. Min. Petrol., 39:21-37.

Rubin J.N., Henry C.D., Price J.G. 1993. The mobility of zirconium and other "immobile" elements during hydrothermal alteration. Chem. Geol., 110:29-47.

Speer J.A. 1982a. Zircon. In: P.H. Ribbe (Ed.) Orthossilicates. Reviews in Mineralogy, 5, Mineralogical Society of America. pp. 67-112.

Speer J.A.1982b. The actinide orthosilicates. In: P.H. Ribbe (Ed.) Orthossilicates. Reviews in Mineralogy, 5, Mineralogical Society of America. pp. 113-135.

Teixeira L.M. 2002. Caracterização de minerais portadores de terras raras e sua aplicação à petrologia e geocronologia de granitos das Subprovíncias Tocantins e Paraná - Goiás. Tese de Doutoramento, Instituto de Geociências, Universidade de Brasília, 356p.

Teixeira L.M. \& Botelho N.F. 1999. Comportamento de elementos terras raras pesadas em zircão, xenotima e torita de granitos e greisens da Subprovíncia Estanífera Paraná - Goiás. Rev. Bras. Geoc., 29:549556.

Teixeira L.M. \& Botelho N.F. 2002. Comportamento cristaloquímico de monazita primária e hidrotermal durante a evolução de granitos e greisens: exemplos das subprovíncias Tocantins e Paranã, Goiás. Rev. Bras. Geoc. 32: 335-342.

Ward C.D., Mc Arthur J.M., Walsh J.N. 1992. Rare earth element behaviour during evolution and alteration of the Dartmoor granite, SW England. Jour. Petrol., 33:785-815.

Wood S.A. 1990. The aqueous geochemistry of the rare earth elements and yttrium - 2: Teoretical predictions of speciation in hydrothermal solutions to $350^{\circ} \mathrm{C}$ at saturated water pressure. Chem. Geol., 88:99125 .

Manuscrito AE030 Aprovado em 30 de outubro de 2006 